$\begin{array}{ll}\text { Research Square } & \begin{array}{l}\text { Preprints are preliminary reports that have not undergone peer review. } \\ \text { They should not be considered conclusive, used to inform clinical practice, } \\ \text { or referenced by the media as validated information. }\end{array}\end{array}$

\title{
Electrospinning Nanofibres Of Pullulan Extracted From Phylloplane Fungus, Aureobasidium Pullulans
}

\author{
Komal Saraf ( $\nabla$ komal.saraf@gmail.com ) \\ Central Institute for Research on Cotton Technology https://orcid.org/0000-0003-1156-3477 \\ N Vigneshwaran \\ Principal Scientist, ICAR -Central Institute of Research on Cotton Technology, Mumbai 400019, India
}

\section{Research}

Keywords: Aureobasidium pullulans, BET surface area, Electrospinning, Nanofibres, NMR, Pullulan

Posted Date: September 18th, 2020

DOI: https://doi.org/10.21203/rs.3.rs-70718/v2

License: @ (1) This work is licensed under a Creative Commons Attribution 4.0 International License. Read Full License 


\section{Abstract}

Aureobasidium pullulans isolated from the phylloplane of Peltophorum tree, produced pullulan, an extracellular polysaccharide. It was grown on three different carbon sources, sucrose, wheat bran and cotton stalk dust, for maximizing the pullulan yield. A. pullulans (67.4 $\mathrm{gL}^{-1}$ ) had the highest yield followed by A. pullulans MTCC 1991 (63.68 $\left.\mathrm{gL}^{-1}\right)$. Pullulan was characterized by X-ray diffractometer (XRD), Brunauer-Emmett-Teller (BET) surface area analyzer, DSC and NMR. Electrospinning of pullulan blended with poly (vinyl alcohol) (PVA) produced bead-less nanofibres. The optimized parameters for electrospinning were $25 \mathrm{kV}$ applied voltage, $0.5 \mathrm{~mL} / \mathrm{h}$ flow rate, $18 \%$ polymer concentration (pullulan + PVA) and $150 \mathrm{~mm}$ tip-to-collector distance. The pullulan nanofibre was characterized by SEM, AFM, BET, contact angle measurement, DSC and CIE color space analyzer. A maximum surface area of $183.4 \mathrm{~m}^{2} / \mathrm{g}$ while the minimum nanofibre diameter (79 $\pm 19 \mathrm{~nm}$ by SEM) was obtained for the electrospun mat of commercial pullulan $+40 \%$ PVA. This work signifies the importance of pullulan extracted from an isolate of Peltopohorum tree for conversion to high surface area nanofibres by electrospinning process.

\section{Introduction}

Pullulan (poly- a-1, 6-maltotriose) is a unique neutral water-soluble exopolysaccharide (EPS) produced in large quantities by microbial fermentation, mostly by Aureobasidium pullulans. Though sucrose and starch are traditional carbon sources, low-cost agricultural wastes like cassava starch residue, wheat bran and rice bran were also being evaluated for pullulan production to make it more economical as against petroleum-derived polymers (Ray et al. 2007). Pullulan is a promising biopolymer having a wide range of commercial and industrial applications in many fields like food science, health care, pharmacy and even in lithography (Singh et al. 2008). Other applications include bio-composite films, oxygen-impermeable coatings, adhesives, plywood, medicine and as fibre (Singh et al. 2008; Leathers et al. 2003; Knapp et al. 2010; Kong et al. 2014). For these special uses, polymer purity and molecular weight are important properties (Pollock et al. 1992; Punnapayak et al. 2003). So, research is also focused on developing an A. pullulans strain with enhanced pullulan productivity and raw material utilization ratio using a new method for genome shuffling of $A$. pullulans N3.387 (Kang et al. 2011).

A. pullulans is a yeast-like Ascomycete of Dothideales Order and Saccotheciaceae Family. They produce poly ( $\beta$-L-malic acid), heavy oil liamocins, siderophore, and aubasidan-like $\beta$-glucan along with pullulan (Prasongsuk et al. 2018). A. pullulans var. pullulans, A. pullulans var. melanogenicum, and $A$. pullulans var. aubasidani are its three varieties based on the differences in its morphological and biochemical properties (Urzi et al. 1999; Yurlova et al. 1996; Zalar et al. 2008). The variety A. pullulans var. melanogenicum differs from the other varieties for its melanin production which occurs in the initial stages of growth and changes the colour of the colonies i.e. olive green to black color. The variety A. pullulans var. aubasidani shows negative response to the assimilation of methyl-a-D-glucoside and lactose and this feature is specific to this variety differentiating it from the other varieties (Yurlova et al. 1996). This strain produces aubasidan-like Pullulan (glucans with a-1, 4-D-, B-1, 6-D- and B-1, 3-D-glycosidic bonds) (Yurlova et al. 1999).

A large variety of plants belonging to temperate, tropical and mediterranean regions have been known to colonize basidiomycetous and ascomycetous yeasts in their phylloplane (Glushakova et al. 2010; SlÁviková et al. 2009; Landell et al. 2010). The commonly found yeasts in the phylloplane were basidiomycetes such as Cryptococcus laurentii, Rhodotorula mucilaginosa, Rhodotorula glutinis and Sporobolomyces roseus (Sharma et al. 2009). Debaryomyces hansenii, Hanseniaspora uvarum, Kazachstania barnetii, Metschnikowia pulcherima, Metschnikowia reukaufii, Pichia membranifaciens, Saccharomyces cerevisiae and various species of Candida were some of the ascomycetous species found in the phylloplane (Koowadjanakul et al. 2011). Limtong et al. (2012) have tested the external surface of plant leaves, usually referred as phylloplane, for the growth of yeast and fungi known to produce pullulan. Youssef et al. (1998) have shown in their study that sucrose and olive oil when used as carbon sources can enhance the production of pullulan by A. pullulans. Kim et al. (2000) have used glucosamine as a carbon source in order to produce high molecular weight pullulan by $A$. pullulans.

As far as the environment is concerned, $A$. pullulans strains are dependent on dead and decaying matter, found mainly on the phylloplane in temperate areas (Punnapayak et al. 2003; Koowadjanakul et al. 2011). They help in keeping the environment clean with constant decomposition of organic material through the production of various enzymes that can breakdown cellulose, pectin, lignin and other plant wastes. This fungus has been isolated from rocks and monuments of moist and temperate conditions leading to blackening of rocks (Urzi et al. 1999). Although its omnivorous appetite is impressive, A. pullulans is a very adaptive fungus and of special interest because of its ability to produce an exopolysaccharide pullulan and many industrial enzymes like amylases, xylanases, pectinases etc. 
Most of these strains were isolated from leaves of tropical plants. By in vitro digestibility study, it was reported that pullulan is less than $10 \%$ digestible and hence could act physiologically as dietary fiber or residue (Kunkel et al. 1994).

Currently, the cost of pullulan is comparatively higher than the petroleum based polymers and hence, their use is limited. To enhance their use, apart from the attempts to reduce their production cost, newer methods of usage need to be explored. Electrospinning can be a good alternative method that produces continuous non-woven biopolymer nanofibres with diameters from micron to nano scale range when an external electric field is imposed on a spinneret containing the biopolymer solution (Liu et al. 2013). Thus produced nanofibres find potential applications in wound dressing, scaffold for tissue engineering, biosensors, drug delivery, gas barrier films and nanocomposites. Since the beginning of the $21^{\text {st }}$ century, electrospun nanofibres have been widely studied and a wide range of applications have been made, such as in energy storage, healthcare, environmental engineering, defense and security (Eslamian et al. 2019). Hence, this work explores the possibility of using cheaper carbon source for pullulan production and their electrospinning potential for production of nanofibre mat and their characterization.

\section{Materials And Methods}

\section{Fungal strains and culture media}

Isolation of pullulan producing fungi was carried out in a minimal salts medium (P2). Medium P2 included (per liter of deionized water): $1 \mathrm{~g}$ of $\left(\mathrm{NH}_{4}\right)_{2} \mathrm{HPO}_{4} ; 0.5 \mathrm{~g}$ of NaCl$; 0.05 \mathrm{~g}$ of $\mathrm{MgSO}_{4} .7 \mathrm{H}_{2} \mathrm{O} ; 2 \mathrm{~g}$ of $\mathrm{K}_{2} \mathrm{HPO}_{4} ; 0.01 \mathrm{~g}$ each of $\mathrm{FeSO}_{4}, \mathrm{MnSO}_{4}$, and $\mathrm{ZnSO}_{4}$; and $\mathrm{HCl}$ to $\mathrm{pH} 7.0$. Sucrose was added to $1 \%(\mathrm{w} / \mathrm{v})$. Agar was included at $15 \mathrm{gL}^{-1}$ for solid plates.

A. pullulans MTCC 1991 was obtained from the culture collection of IMTECH Chandigarh, India. P2 medium with 5\% sucrose was used to carry out submerged fermentation (SF). Wheat Bran (WB) and Cotton Stalk Dust (CSD) were obtained from the local market in Mumbai, India and used as solid substrate and sole carbon source for Solid State Fermentation (SSF). A basal production medium for SSF was prepared as follows: $3.5 \mathrm{~g}$ of sodium glutamate; $5 \mathrm{~g}$ of $\mathrm{K}_{2} \mathrm{HPO}_{4} ; 2 \mathrm{~g}$ of $\mathrm{KH}_{2} \mathrm{PO}_{4}, 2 \mathrm{~g}$ of $\mathrm{MgSO}_{4} ; 1 \mathrm{~g}$ of NaCl and $0.5 \mathrm{~g}$ of FeSO $7 \mathrm{H}_{2} \mathrm{O}$ per liter and $\mathrm{pH}$ adjusted to 6.5 with $1 \mathrm{~N} \mathrm{HCl}$. Solid substrate was prepared by taking $20 \mathrm{~g}$ of substrates in $250 \mathrm{~mL}$ Erlenmeyer flasks and amended with $40 \mathrm{~mL}$ of basal medium (1:2 ratio, w/v) and thoroughly mixed. The prepared solid substrate was sterilized in an autoclave at $121^{\circ} \mathrm{C}$ for $20 \mathrm{~min}$ and cooled to ambient temperature. All the chemicals used to make media were of analytical grade.

\section{Isolation of pullulan producing fungi by selective enrichment}

Leaves (old and young) were removed from Peltophorum tree and soaked in sterile water for 3 days at $25^{\circ} \mathrm{C}$, and then $0.1 \mathrm{~mL}$ of soaked water was transferred to $10 \mathrm{~mL}$ of $\mathrm{P} 2$ minimal salts medium $(\mathrm{pH} 4)$ containing $1 \%(\mathrm{w} / \mathrm{v})$ sucrose and $10 \mu \mathrm{g} / \mathrm{mL}$ of chloramphenicol. After 2 days of shaking of $\mathrm{P} 2$ medium broth at $25^{\circ} \mathrm{C}$, the turbid culture was allowed to stand undisturbed for 20 min to allow filaments and aggregates to settle to the bottom. About $10 \mu \mathrm{L}$, from the upper partially clarified phase that, was enriched for yeast-like cells were spread onto agar plates containing P2 medium ( $\mathrm{pH} 5), 1 \%(\mathrm{w} / \mathrm{v})$ sucrose and $10 \mu \mathrm{g} / \mathrm{mL}$ of chloramphenicol. After 4 days, independent colonies were purified by sub-culturing.

\section{Pullulan production}

The fungal inoculums of $A$. pullulans MTCC 1991 and the isolates were prepared as follows. A loop full of each culture was inoculated in basal medium and incubated at $30{ }^{\circ} \mathrm{C}$ for $48 \mathrm{~h}$. About $0.5 \mathrm{~mL}$ culture was added to $40 \mathrm{~mL}$ of $\mathrm{P} 2$ ( $5 \%$ sucrose) liquid medium and the cultures were shaken at $200 \mathrm{rpm}$ at $25^{\circ} \mathrm{C}$ for $66 \mathrm{~h}$ for SF. While for SSF, $2 \mathrm{~mL}$ of $48 \mathrm{~h}$ old cultures grown on basal medium was inoculated in $20 \mathrm{~g}$ of solid substrates with $40 \mathrm{~mL}$ basal medium and incubated at $30^{\circ} \mathrm{C}$ for 7 days. All the samples were analyzed in triplicates and the yields were expressed as average \pm standard deviation (S.D.).

\section{Biochemical Analysis of the substrates used for SSF}

To determine the biochemical composition of WB and CSD, moisture content was determined by drying in hot air oven at $105^{\circ} \mathrm{C}$ for $5 \mathrm{~h}$, protein estimation (total nitrogen x 5.7 for WB and 6.25 for CSD) was determined by Kjeldahl method using Kelplus ${ }^{\circledR}$ Instrument (Pelican Equipments, Chennai, India) and ash content was determined by heating in a muffle furnace at $550 \pm 25^{\circ} \mathrm{C}$ for $3 \mathrm{~h}$. Crude fibre was determined by Weende's method of acid and alkali digestion using Fibraplus ${ }^{\circledR}$ Instrument (Pelican Equipments, Chennai, India). All the parameters were analyzed in triplicates and were expressed as average \pm (S.D.).

\section{Downstream processing for extraction of EPS}


The samples of SF, where $5 \%$ sucrose as carbon source was diluted with 1 volume of deionized water and centrifuged, and the EPS were recovered from the clarified broth by precipitation with 1 volume of Isopropyl alcohol (IPA). The precipitate was removed and dried to constant weight in an oven at $80^{\circ} \mathrm{C}$. In case of SSF, the fermented mass was washed thoroughly with 5 volumes of deionized water by shaking at $250 \mathrm{rpm}$ for $2 \mathrm{~h}$. Cheese cloth was used for coarse filtration and centrifugation at $5488 \mathrm{xg}$ for $45 \mathrm{~min}$ at $4{ }^{\circ} \mathrm{C}$ for finer particles separation. Pullulan was precipitated using 2 volumes of IPA after addition of $2 \% \mathrm{KCl}$ in the aqueous extracts. The precipitated pullulan was collected on pre-weighed weighing bottle and dried at $80^{\circ} \mathrm{C}$ till constant weight. The yield of pullulan was expressed as $\mathrm{gL}^{-1}$ of production medium in SF and as $\mathrm{gL}^{-1}$ of basal medium in SSF.

\section{Screening of isolates for pullulan production}

The extracted EPS from the isolates were tested for the presence of pullulan on the basis of the set of identification tests like solubility in water, $\mathrm{pH}$ of $10 \%$ solution in the range of 5-7, white precipitate formation with Polyethylene glycol 600 (PEG 600) and functional group analysis by Fourier transform infrared (FT-IR) (IR Prestige $21^{\circledR}$ model) by KBr pellet method. For PEG 600 test, $2 \mathrm{~mL}$ of PEG 600 was added to $10 \mathrm{~mL}$ of $2 \%$ aqueous EPS solution, development of white precipitate indicated a positive test for pullulan. FT-IR spectra were recorded with the following parameters: 64 scans; resolution, $4 \mathrm{~cm}^{-1}$ over the $\mathrm{KBr}$ pellet. Pullulan sample $(1 \mathrm{mg})$ was manually well blended with $100 \mathrm{mg}$ of $\mathrm{KBr}$ powder. These mixtures were then desiccated overnight at $50^{\circ} \mathrm{C}$ under reduced pressure prior to FTIR measurement. The pullulan extracted from A. pullulans MTCC 1991 and commercial pullulan were used for comparison. The cultures, that gave positive results for the above mentioned tests, were processed further for morphological and biochemical analysis for identification.

\section{Morphological and biochemical analysis for identification}

Identification of the cultures and assessment of nutritional physiology were carried out as per the identification key provided in the literature (Yurlova et al. 1996; Yurlova et al. 1999). Morphology of the colonies was studied on different culture media: Potato Dextrose Agar (PDA, Himedia), Blakeslee's Malt Extract Agar (MEA) and Yeast Morphology Agar (YMA, Himedia) and incubated at $30{ }^{\circ} \mathrm{C}$ for 7-14 days in darkness. Morphological characteristics of the isolated fungal cells were studied under light microscopy in slide culture on PDA at $30^{\circ} \mathrm{C}$ for 7 days. Wet mount of the cultures were performed to determine the structure of hyphae and conidiophore. The fungal isolate was also sent to National Fungal Culture Collection of India (NFCCI)-A National Facility, Agharkar Research Institute, Pune, India for morphological characterization. Assimilation tests of carbon and nitrogen compounds were tested in liquid media of Yeast Nitrogen Base (YNB) and Yeast Carbon Base (YCB) respectively at $30^{\circ} \mathrm{C}$ up to 14 days. The stock solutions were sterilized by filtration and refrigerated until further use. Carbon sources used are $2 \%$ each of D-Xylose, D-Arabinose, Ethanol, D (+) Melibiose, a methyl-D-glucoside and DLactose whereas nitrogen source tested is D-glucosamine (Yurlova et al. 1996; Kurtzman et al. 2011). Urease production was tested in Christensen's Urea Broth and incubate at $37^{\circ} \mathrm{C}$ for $48 \mathrm{~h}$. Citrate utilization was studied using Simmon Citrate Agar (Himedia ${ }^{\circledR}$ ) incubated at $30^{\circ} \mathrm{C}$ for 7 days. Growth at $37^{\circ} \mathrm{C}$ was tested in Malt Extract Broth incubated for 7 days. Solubilization of $\mathrm{CaCO}_{3}$ was performed in $\mathrm{CaCO}_{3}$ agar medium (Himedia ${ }^{\circledR}$, India). The fungal isolate was sent to National Centre for Microbial Resource (NCMR), NCCS, Pune for sequencing and deposition.

\section{Characterization of pullulan}

Extracted pullulan was subjected to X-ray diffractometer (XRD, X'pert Pro, PANalytical $\left.{ }^{\circledR}\right)$ to study the crystallinity. Wide angle X-ray diffraction patterns were obtained with nickel filtered $\mathrm{Cu} \mathrm{Ka}(\lambda=1.54 \AA$ ) radiation and analyzed using automatic powder diffraction (APD) software. The diffracted intensities were recorded from $5 \rrbracket$ to $80 \otimes 2 \theta$ angles. The crystallite height $\left(\mathrm{I}_{002}\right)$, measured at the peak around $20 \otimes 2 \theta$ angle, and amorphous height $\left(\mathrm{l}_{\mathrm{am}}\right)$, measured at the valley around $11 \otimes 2 \theta$ angle, were used to calculate the apparent crystallinity index (apparent Cr.I.) using the empirical method (Choudhury et al. 2013) as per the equation (1).

$$
\text { Cr. I }=\left(\frac{\mathrm{I} 002-\mathrm{Iam}}{\mathrm{I} 002}\right) * 100
$$

The average pore size, total pore volume and specific surface area were determined by Brunauer-Emmett-Teller (BET) method. Samples were degassed at $160^{\circ} \mathrm{C}$ for $3.5 \mathrm{~h}$ under vacuum before analysis. BET analyses were performed using Quantachrome Nova model and Novawin software and using the equation (2). 
Where, $\mathrm{P}=$ partial vapor pressure of adsorbate gas in equilibrium with the surface at $77.4 \mathrm{~K}$ (boiling point of liquid nitrogen), in Pascals; $\mathrm{Po}=$ saturated pressure of adsorbate gas, in Pascals; $\mathrm{Va}=$ volume of gas adsorbed at standard temperature and pressure (STP) [273.15 $\mathrm{K}$ and atmospheric pressure $\left(1.013 \times 10^{5} \mathrm{~Pa}\right)$ ], in $\mathrm{mL} ; \mathrm{Vm}=$ volume of gas adsorbed at STP to produce an apparent monolayer on the sample surface, in $\mathrm{mL} ; \mathrm{C}=$ dimensionless constant that is related to the enthalpy of adsorption of the adsorbate gas on the powder sample. A value of $\mathrm{Va}$ is measured at each of not less than 3 values of P/Po. Then the BET value calculated as given in equation (2) is plotted against P/Po according to the equation (3). This plot should yield a straight line usually in the approximate relative pressure range 0.05 to 0.3 . All the parameters were analyzed in triplicates and were expressed as average \pm standard deviation (S.D.).

$$
\frac{1}{V a\left(\frac{P o}{P}-1\right)}
$$

The thermal properties of the extracted pullulan were evaluated by a differential scanning calorimeter (Mettler Toledo TC-15 TA). Samples were placed onto aluminum crucibles and then the runs were carried out from room temperature to $450{ }^{\circ} \mathrm{C}$ at a heating rate of $10{ }^{\circ} \mathrm{C} \mathrm{min}^{-1}$ under nitrogen atmosphere.

For ${ }^{1} \mathrm{H}$-NMR spectroscopy, the solutions were prepared by dissolving 5 to $9 \mathrm{mg}$ of commercial as well as lyophilized pullulan samples per $\mathrm{mL}$ of $\mathrm{D}_{2} \mathrm{O}$ (Sigma Aldrich, USA) and analyzed using Agilent $600 \mathrm{MHz}$ AR Spectrophotometer, USA. The raw data was processed using the $\mathrm{Vnmrj}^{\circledR}$ software.

\section{Electrospinning of pullulan}

The extracted pullulan from A. pullulans MTCC 1991 and A. pullulans were dissolved in distilled water with the help of heating and magnetic stirring. Final concentration was adjusted to $18 \%$ for extracted pullulan and $12 \%$ for commercial pullulan for electrospinning. For the electrospinning solution, pH was measured by pH meter (El Model - 1012E), particle size and zeta potential by using Zeta Sizer Nicomp $^{\text {TM }} 380$ ZLS (Santa Barbara, California, USA), conductivity by using Conductivity meter (Eutech Instruments, Con 2700) and viscosity by Brookefield DV III Ultra Programmable Rheometer. All the parameters were analyzed in triplicates and were expressed as average \pm S.D. The electrospinning was carried out with varying proportions PVA and pullulan for bead-less nanofibre formation. The inhouse assembled electrospinning system consisted of a fume hood housing the equipment, syringe pump (New Era Pump Systems, Inc.) with a syringe having a metallic needle, a controllable high-voltage source ( 0 to $50 \mathrm{kV}$ ) connected to the needle, and a grounded copper foil wrapped collector plate for collection of the fibrous mats. Optimization experiments were carried out by varying the following process conditions: $15-20 \mathrm{~cm}$ tip to collector distance (TCD); 0.2 to $1.0 \mathrm{~mL} / \mathrm{h}$ flow rate; and 15 to $25 \mathrm{kV}$ voltages to obtain the bead-less nanofibres.

\section{Characterization of pullulan nanofibre mats}

The morphology of electrospun nanofibres was studied using a scanning electron microscope (SEM), Philips XL-30, with an accelerating voltage of $12 \mathrm{kV}$. Each sample was coated with a thin layer of conducting material (gold/palladium) using a sputter coater before SEM analysis. The SEM images were analyzed in Image $J^{\circledR}$ software to determine the average diameter of nanofibres. The morphology of nanofibres was observed and fibre diameter, roughness and surface area were measured using Atomic Force Microscope (AFM), (dilnnova ${ }^{\circledR}$ SPM Veeco, Santa Barbara, CA, US), equipped with a $90 \mu \mathrm{m}$ scanner by tapping mode in ambient condition. The silicon nitride cantilever with a spring constant of $40 \mathrm{Nm}^{-1}$ was used for scanning. The scan rate of $1.0 \mathrm{~Hz}$ and 512 lines per $10 \mu \mathrm{m}$ were used to optimum contrast. No filtering was done during scanning. The average pore size, total pore volume and specific surface area were determined by BET analyzer. Samples were degassed at $160{ }^{\circ} \mathrm{C}$ for $3.5 \mathrm{~h}$ under vacuum before analysis. All the parameters were analyzed in triplicates and were expressed as average \pm standard S.D.

Water contact angle was measured using GBX ILMS Version 3.6 instrument to study the hydrophilic nature of the electrospun nanofibre mats. Using a microsyringe, $5 \mu \mathrm{L}$ deionized water was dropped perpendicularly to each surface of the mat placed on a horizontal glass sheet. Then, the images of water drops on the surface of the mat were recorded and analyzed. The thermal properties of the nanofibre 
mats were evaluated by a differential scanning calorimeter (Mettler Toledo TC-15 TA ${ }^{\circledR}$ ). Samples were cut into small pieces and placed onto aluminum crucibles and then the runs were carried out from room temperature to $450^{\circ} \mathrm{C}$ at a heating rate of $10^{\circ} \mathrm{C} \mathrm{min}{ }^{-1}$ under nitrogen atmosphere. For determining the grey values of developed electrospun nanofibre mats, the CIE (International Commission of Illumination) color space coordinates were determined. A color is defined by its RGB values which give the amount of red, green and blue in a particular color. In CIE $L^{*} a * b *$ color space values, $L *$ stands for lightness, $a *$ and $b$ * for the green-red and blue-yellow color components and $\Delta \mathrm{L}$ represents brightness difference between samples. The magnitude of color difference was quantified as $\Delta \mathrm{E}$.

\section{Results And Discussion}

\section{Isolation of pullulan producing fungi by selective enrichment}

Selective enrichment of the extract from Peltophorum leaves resulted in five isolates namely OL1, OL2, OL3 obtained from old leaf and YL1 and YL2 obtained from young leaf respectively.

\section{Discussion:}

All isolates were maintained on P2 as well as PDA media. P2 medium was used as it contained minimal salts medium plus sucrose and low $\mathrm{pH}$, which acted as basis for selective enrichment. Chloramphenicol was added to prevent bacterial growth during enrichment and isolation. After incubation for 2 days at $30^{\circ} \mathrm{C}$, the color of the colony ranged from off-white or light beige to pale pink to green and black appeared.

\section{Production of pullulan and screening of isolates for pullulan production}

The five isolates were subjected to screening for pullulan production by SF and SSF. Basal medium consisting of trace elements, mineral nutrients and buffering agents was used to supplement the solid substrate for pullulan production. Pullulan yield was higher for WB by SSF as compared to $5 \%$ Sucrose in SF. CSD could not be utilized to produce pullulan, as the precipitates extracted from the cultures post fermentation were insoluble in water which is a preliminary confirmatory qualitative test for identification of pullulan (Table 1).

Table 1 EPS from A. pullulans MTCC 1991 and isolates using different carbon sources and qualitative tests for identification of pullulan

\begin{tabular}{|c|c|c|c|c|c|c|c|}
\hline \multirow{2}{*}{$\begin{array}{l}\text { Sr. } \\
\text { No. }\end{array}$} & \multirow{2}{*}{$\begin{array}{l}\text { Culture / Sample } \\
\text { details }\end{array}$} & \multicolumn{3}{|c|}{ EPS yield $\left(\mathrm{gL}^{-1} \pm \mathrm{SD}\right)$} & \multirow{2}{*}{$\begin{array}{l}\text { Solubility in } \\
\text { water }\end{array}$} & \multirow{2}{*}{$\begin{array}{l}\text { Precipitate with PEG } \\
600\end{array}$} & \multirow[t]{2}{*}{$\mathrm{pH}$} \\
\hline & & $\begin{array}{l}\text { Sucrose } \\
\text { (SF) }\end{array}$ & WB (SSF) & CSD (SSF) & & & \\
\hline 1 & $\begin{array}{l}\text { A. pullulans MTCC } \\
1991\end{array}$ & $1.83 \pm 0.15$ & $63.68 \pm 2$ & $\begin{array}{l}15.15 \pm \\
0.25\end{array}$ & + & + & 6.5 \\
\hline 2 & OL1 & $2.28 \pm 0.2$ & $\begin{array}{l}28.70 \pm \\
0.66\end{array}$ & $\begin{array}{l}12.90 \pm \\
0.14\end{array}$ & - & NA & NA \\
\hline 3 & OL2 & $1.93 \pm 0.19$ & $44.43 \pm 1.5$ & $\begin{array}{l}10.08 \pm \\
0.16\end{array}$ & - & NA & NA \\
\hline 4 & OL3 & $0.55 \pm 0.22$ & $67.4 \pm 2.2$ & $11.73 \pm 0.2$ & + & + & 5 \\
\hline 5 & YL1 & $0.69 \pm 0.28$ & $30.2 \pm 0.85$ & $\begin{array}{l}14.08 \pm \\
0.23\end{array}$ & - & NA & NA \\
\hline 6 & YL2 & $0.6 \pm 0.21$ & 35.25 & $9.45 \pm 0.1$ & - & NA & NA \\
\hline 7 & Commercial pullulan & NA & NA & NA & + & + & 5.5 \\
\hline
\end{tabular}

Table 2 Biochemical Analysis of the substrates used for SSF 


\begin{tabular}{|clll|}
\hline Sr. No. & Constituents & $\begin{array}{l}\text { Average } \\
\text { WB }(\%) \pm \text { SD }\end{array}$ & $\begin{array}{l}\text { Average } \\
\text { CSD }(\%) \pm \text { SD }\end{array}$ \\
\hline 1 & Moisture & $8.08 \pm 0.55$ & $9.58 \pm 2.2$ \\
\hline 2 & Crude fibre & $10.25 \pm 2$ & $30.91 \pm 4.5$ \\
\hline 3 & Nitrogen & $3.85 \pm 0.63$ & $1.5 \pm 0.17$ \\
\hline 4 & Crude Protein & $21.9 \pm 3.6$ & $9.37 \pm 1.1$ \\
\hline 5 & Total Ash & $5.5 \pm 0.76$ & $10.93 \pm 3.3$ \\
\hline
\end{tabular}

As per the results in Table 1, various cultures including A. pullulans MTCC 1991 as well as isolates were screened for the production of pullulan. The yield obtained for A. pullulans MTCC 1991 using WB in SSF was found to be $63.68 \mathrm{gL}^{-1}$. Also the isolate, OL3 gave a yield of $67.4 \mathrm{gL}^{-1}$ using WB in SSF. As seen in Fig. 1, the FTIR spectra showed strong absorption at around $3400 \mathrm{~cm}^{-1}$ indicated that all the pullulan had some repeating units of $-\mathrm{OH}$ as in sugars. The other strong absorption at $2926 \mathrm{~cm}^{-1}$ indicated a SP3-hybridisation of C-H bond, around $1600 \mathrm{~cm}^{-1}$ for the O-C-O bond, around $1300 \mathrm{~cm}^{-1}$ for C-O-H bond, $1000 \mathrm{~cm}^{-1}$ for the $\mathrm{C}-\mathrm{O}$ bonds in the alkane compounds existed in all the samples. Fig. 1 FTIR spectra of Commercial Pullulan (a), Pullulan of A. pullulans MTCC 1991 (b) and EPS of OL3 (c)

\section{Discussion:}

SSF has gained importance recently due to several advantages over SF such as lower investment, easy operation and simplified downstream processing. Two undesirable features of SF of $A$. pullulans are reported. The decrease in culture viscosity during submerged growth resulted in decrease of average molecular weight of the accumulated extracellular pullulan from $3 \times 10^{6}-6 \times 10^{6}$ to $1 \times 10^{5}-2 \times$ $10^{5} \mathrm{Da}$. Also, there is a simultaneous synthesis of dark melanin-like pigment, which contaminates the pullulan (Pollock et al. 1992b; Punnapayak et al. 2003).

As per the results in Table 1, the yield obtained for A. pullulans MTCC 1991 using WB in SSF was more than the reported commercial production rate (25 to $61 \mathrm{gL}^{-1}$ ) in liquid medium (SF) (Pollock et al. 1992; Choudhury et al. 2013; Karim et al. 2011). Earlier research reported the use of jackfruit seed powder based medium components for pullulan production by Aureobasidium pullulans and the maximum pullulan concentration of $17.95\left(\mathrm{gL}^{-1}\right)$ only was produced in the validation experiment (Sharmila et al. 2013). Also the isolate, OL3 gave more yield than A. pullulans MTCC 1991 using WB in SSF. Thus, WB could be a promising economic substrate for production of pullulan in SSF. Thus the above results support the finding that WB has more than $50 \%$ nutritional value (Table 2) as compared to CSD, making it a good solid substrate for pullulan production by SSF. Pullulan content and color depends on the strain of microorganisms used and the chemical composition of the substrate. Earlier work reported the preference of glucose over sucrose for production of pullulans by $A$. pullulans (Punnapayak et al. 2003).

As seen in Fig. 1, the FTIR spectrum of the commercial grade pullulan matches well with the EPS produced by A. pullulans MTCC 1991 and the isolate, thereby confirming the production of pullulan.

\section{Morphological and biochemical analysis for identification}

The selected fungal isolate for pullulan production, OL3 was subjected to identification based on morphological and nutritional physiological characteristics. Fungal growth in standard conditions (PDA at $30^{\circ} \mathrm{C}$ ) occurred within $48 \mathrm{~h}$ that were not pigmented or light pink at the beginning, later became olive green-black. As per Fig. 2, A. pullulans MTCC 1991 and OL3 had septate hyphae of diameter more than $2 \mu \mathrm{m}$. The conidiophore bearing conidia were observed for A. pullulans MTCC 1991 and prototunicate asci and blastic conidiogenesis of OL3 were also observed. Growth on different cultural media (PDA, MEA and YMA) affected both the morphology and pigment production. Variation in colony color was also detected when the fungi were cultivated on MEA for seven days.

Following the identification keys provided earlier (de Hoog et al. 1994) and morphological appearance, the isolate namely OL3 was identified as Aureobasidium pullulans (de Bary \& Lowenthal) G. Arnaud. This has also been confirmed by the morphological characterization carried out by National Fungal Culture Collection of India (NFCCI)-A National Facility, Agharkar Research Institute, Pune, 
India. As per the sequencing results done by Internal transcribed spacer (ITS) method, it was found that the strain showed $99 \%$ similarity with Aureobasidium melanogenum CBS 105.22, carried out at NCMR-NCCS, Pune, India. The same strain has been deposited at NCCS, Pune, with the accession number MCC 1868.

Table 3 The nutritional physiology profiles of $A$. pullulans MTCC 1991 and isolate OL3

\begin{tabular}{|lll|}
\hline Characteristics & A. pullulans MTCC 1991 & Isolate OL3 \\
\hline Carbon sources & & + \\
\hline D - Xylose & + & + \\
\hline D - Arabinose & + & + \\
\hline Ethanol & + & + \\
\hline D (+) Melibiose & + & + \\
\hline a methyl-D-glucoside & + & + \\
\hline D-Lactose & + & + \\
\hline D-glucosamine & + & + \\
\hline Citrate & + & + \\
\hline Urea hydrolysis & + & \\
\hline Temperature tolerance & & + \\
\hline $25^{\circ} \mathrm{C}$ & + & + \\
\hline $30^{\circ} \mathrm{C}$ & + & - \\
\hline $37^{\circ} \mathrm{C}$ & - & - \\
\hline $\mathrm{CaCO}_{3}$ Solubilization & - & + \\
\hline
\end{tabular}

\section{Discussion:}

The nutritional physiology profiles of isolate OL3 corresponded well to those of A. pullulans MTCC 1991 as shown in Table 3. Cultures equivalent to identified strain of culture Aureobasidium pullulans (de Bary \& Lowenthal) are NCIM 1048, ATCC 42023, DSM 3042, ATCC 62922.

\section{Physical characterization of pullulan}

The XRD patterns of pullulan extracted from A. pullulans MTCC 1991 and A. pullulans (Fig. 3) had a very distinct broad valley and peak, indicating the amorphous and crystalline nature of the material. The deepest point of the valley was considered for calculation purpose of amorphous region. The apparent crystallinity indices of commercial pullulan, A. pullulans MTCC 1991 and A. pullulans were calculated as $29.0 \%, 45.8 \%$ and $18.3 \%$, respectively.

As seen in Table 4, the average pore radius of commercial pullulan and that of extracted pullulan from A. pullulans MTCC 1991 as well as isolates was the same around 24-30 $\AA$. Similarly the total pore volume was found to be in the range 0.02 to $0.075 \mathrm{cc} \mathrm{g}^{-1}$.

Table 4 BET analysis and solution properties of pullulans 


\begin{tabular}{|c|c|c|c|c|c|c|c|c|c|}
\hline $\begin{array}{l}\text { Sr. } \\
\text { No. }\end{array}$ & $\begin{array}{l}\text { Source of } \\
\text { Pullulan }\end{array}$ & $\begin{array}{l}\text { Average } \\
\text { Pore } \\
\text { Radius ( }(\AA) \\
\pm \text { SD }\end{array}$ & $\begin{array}{l}\text { Total Pore } \\
\text { Volume }(\mathrm{cc} / \mathrm{g}) \\
\pm \text { SD }\end{array}$ & $\begin{array}{l}\text { Surface } \\
\text { area }\left(\mathrm{m}^{2} / \mathrm{g}\right) \\
\pm \mathrm{SD}\end{array}$ & $\mathrm{pH}$ & $\begin{array}{l}\text { Mean } \\
\text { diameter } \\
\text { by DLS } \\
(\mathrm{nm}) \pm \\
\text { SD }\end{array}$ & $\begin{array}{l}\text { Zeta } \\
\text { potential } \\
(\mathrm{mV}) \pm \\
\mathrm{SD}\end{array}$ & $\begin{array}{l}\text { Viscosity } \\
\text { (CP) } \pm \\
\text { SD }\end{array}$ & $\begin{array}{l}\text { Conductivity } \\
\text { (mS) } \pm \text { SD }\end{array}$ \\
\hline 1 & Commercial & $24.34 \pm 0.04$ & $0.02167 \pm 0.01$ & $17.806 \pm 1.95$ & $6.5 \pm 0.1$ & $\begin{array}{l}22.8 \pm \\
1.8\end{array}$ & $\begin{array}{l}6.51 \pm \\
0.35\end{array}$ & $\begin{array}{l}74.6 \pm \\
11\end{array}$ & $\begin{array}{l}47.63(\mu S) \pm \\
0.53\end{array}$ \\
\hline \multirow[t]{2}{*}{2} & $\begin{array}{l}\text { A. pullulans } \\
\text { MTCC }\end{array}$ & $29.17 \pm 0.07$ & $0.06847 \pm 0.005$ & $46.949 \pm 1.4$ & $7.6 \pm 0.12$ & $\begin{array}{l}697.9 \pm \\
21\end{array}$ & $\begin{array}{l}28.04 \pm \\
1.4\end{array}$ & $144 \pm 14$ & $9.673 \pm 1.85$ \\
\hline & 1991 & & & & & & & & \\
\hline 3 & A. pullulans & $29.59 \pm 0.08$ & $0.06313 \pm 0.01$ & $42.679 \pm 1.75$ & $7.3 \pm 0.15$ & $\begin{array}{l}527.9 \pm \\
18\end{array}$ & $\begin{array}{l}11.34 \pm \\
0.75\end{array}$ & $\begin{array}{l}265.2 \pm \\
22\end{array}$ & $13.66 \pm 2.5$ \\
\hline
\end{tabular}

As seen in the thermograms (Fig. 4), $\mathrm{T}_{\mathrm{g}}$ values were 41,43 and 43 for commercial pullulan, pullulans from A. pullulans MTCC 1991 pullulan and $A$. pullulans respectively. The range of melting temperature was found to be from 107 to $152^{\circ} \mathrm{C}$.

Structural characterization of pullulan was carried out by ${ }^{1} \mathrm{H}-\mathrm{NMR}$ and ${ }^{13} \mathrm{C}-\mathrm{NMR}$ spectroscopy and compared with that of commercial pullulan. Four chemical signals were displayed in the anomeric region between 4.4 to $5.3 \mathrm{ppm}$ due to the four sugar repeating unit present in the pullulan polysaccharide. Signals were observed at 1.2 and $1.1 \mathrm{ppm}$ was due to 6-deoxy-d-altrose present in the polysaccharide as shown in Fig. 5a. This confirms the presence of the major components of the pullulan structure in the extracted polymer as compared with the commercial in ${ }^{1} \mathrm{H}-\mathrm{NMR}$ spectra. For all the extracted pullulans (Fig. $5 \mathrm{~b}$ ), it was found that there was splitting of C-6 (peaks between 60 to $62 \mathrm{ppm}$ ) and C-4 (peaks between 71 to $79 \mathrm{ppm}$ ) were due to C-1 of $(1 \rightarrow 4$ ) linked glucose unit. C-6 signals arrived at around $60 \mathrm{ppm}$ are due to two kinds of 1,4 linked a-D glucose, whereas the signal at around 69 ppm corresponds to C-6 of the 1, 6 linked a-D glucose. There was a single peak between 82 and $88 \mathrm{ppm}$ at around $84 \mathrm{ppm}$ which explained that very few of the sugar residues were available in furanose form and most of them were in pyranose form in biopolymer. Anomeric a $(1 \rightarrow 6)$ appeared by peak at around 99 ppm. Signals were detected in the 57.7-64.7 regions indicating that some C-6 positions were non-glycosylated. Anomeric a $(1 \rightarrow 6)$ was indicated by peak resonance at $99.73 \mathrm{ppm}$ whereas anomeric $\mathrm{a}(1 \rightarrow 4)$ was indicated by peak resonance at 100-101 ppm. None of the peaks were obtained between 93 and 97 ppm indicating the absence of oligomers.

\section{Discussion:}

As per the results of XRD spectra, the apparent crystallinity indices of commercial pullulan, A. pullulans MTCC 1991 and A. pullulans match well with the literature reported values (Wu et al. 2013; Xiao et al. 2015). Although a highly crystalline polymer is stronger but it loses its flexibility since it is too brittle and cannot be reused as a plastic. The amorphous nature of the polymer gives it the ability to bend without breaking. It's important to know that fibres are always composed of polymers which are arranged into crystals showing regular arrangement (Zalar et al. 2008). Based on the above mentioned points, pullulan was found to be a balanced polymer.

The technique is named after its inventors; BET is the most frequent method for determination of specific surface area of porous materials. The measurement is based on physical adsorption of gas on the surface of the sample. As seen in Table 4, the average pore radii and total pore volume of the commercial pullulan and extracted samples were similar. But, the surface area for extracted pullulan was more than twice the surface area of commercial pullulan. It is also evident that particle size, charge, viscosity and conductivity, of the lyophilized pullulans from A. pullulans MTCC 1991 and A. pullulans, were significantly larger than commercial pullulan. The increased amount of charge as seen from the values of zeta potential corresponds to the increased conductivity of the extracted pullulans. This increased conductivity in turn would help in the process of electrospinning thereby giving larger surface area, pore size and pore volume.

The glass transition temperature $\left(\mathrm{T}_{\mathrm{g}}\right)$ was taken as the mid-point of the change of slope in the DSC curves. As per the literature depending on different sources of pullulan, the range of $T_{g}$ of pullulan was from 38 to $59^{\circ} \mathrm{C}$ (Xiao et al. 2015). As seen in the thermograms (Fig. 4), $T_{g}$ values of the commercial and extracted samples matched well with the literature and also fall in the normal range. The change in melting point reflects the change in crystallinity of the polymer extracted from the cultures (Li et al. 2017). 
Pullulan is a glucose polysaccharide of $20 \mathrm{kDa}$, consisting of maltotriose $\left[\mathrm{a}(1,4)\right.$ units attached by $\mathrm{a}(1,6)$ linkages]. Hence the ${ }^{13} \mathrm{C}$ spectrum should yield 18 resonances (Li et al. 2017; Arnosti et al. 1995). But, achieving all 18 peaks is difficult as there are chances for overlapping. All the peak resonances match well with the commercial pullulan and other references showing NMR spectra of pullulan except that there was absence of furanose form of sugar residues in them as seen in Fig. 5b (Ye et al. 2008; Sugumaran et al. 2014; Sugumaran et al. 2013). The additional peaks in the extracted pullulan might be due to the impurities present in the samples.

\section{Electrospinning of pullulan}

The $\mathrm{pH}$ of the solution was found to be on the acidic side for commercial pullulan but neutral or slightly alkaline for the extracted pullulan. The zeta potential and conductivity of extracted pullulans were higher than that of commercial pullulan. The viscosity of extracted pullulans was higher than that of commercial pullulan. All the values are given in Table 4. Taking into account, $\mathrm{pH}$, zeta potential, conductivity and particle size of the extracted pullulans, there was a need for a carrier polymer to aid the process of electrospinning to produce nanofibers for which PVA was chosen.

Throughout the experiment the applied voltage, flow rate, polymer concentration and TCD were fixed at $20 \mathrm{kV}, 0.5 \mathrm{~mL} \mathrm{~h}^{-1}, 18 \%$ pullulan and $15 \mathrm{~cm}$, respectively. The proportion of PVA required to produce nanofibres was found to be $50 \%$ for pullulan extracted from A. pullulans where as it was $40 \%$ for pullulan extracted from A. pullulans MTCC 1991. But, commercial pullulan gave beaded nanofibres with PVA (Fig. 6).

\section{Discussion:}

Acidic solution tend to give better electrospinning due to presence of $\mathrm{H}^{+}$ion concentration aiding in attraction of polymer solution droplet from the tip of the collector towards the negative electrode when electric field is applied. So, the pullulan with neutral to alkaline $\mathrm{pH}$ was not getting electrospun without any carrier polymer. Higher zeta potential and conductivity let to increasing the charge carrying ability of the polymer jet which subjected to higher tension under the electric field, resulted in poor fibre formation. The viscosity range of different polymer solutions at which electrospinning is done is a major variable. Higher viscosity of extracted pullulans aided them to give continuous smooth fibres when electrospun whereas commercial pullulan having lower viscosity would give beaded fibres. PVA was used as a carrier polymer as it is relatively inexpensive, chemically and thermally stable, and not degradable under most physiological conditions. An earlier work reported the production of gelatin/polyurethane blended nanofiber by electrospinning having the potential application for use as a wound dressing, wherein the polyurethane was used to reduce the hydrophilicity of gelatin (Kim et al. 2009). Yet another work reported the production of a composite electrospun nanofibre using pullulan, PVA and montmorillonite clay having enhanced thermal stability and mechanical property (Islam et al. 2012).

The morphology of electrospun nanofibres can be affected by electrospinning instrument parameters including applied voltage, tip to collector distance (TCD), flow rate and solution parameters such as polymer concentration. Earlier work reported the electrospinning of chitosan from its solutions in $2 \%$ aqueous acetic acid by adding PVA as a "guest" polymer (Zhang et al. 2007).

\section{Characterization of nanofibre mats}

The SEM images showed smooth bead free nanofibres for electrospun pullulan extracted from A. pullulans and A. pullulans MTCC 1991 but commercial pullulan gave beaded nanofibres (Fig. 6). As analyzed in Image $\mathrm{J}^{\circledR}$ software, the average diameter range of nanofibres was found to be 130 to $179 \mathrm{~nm}$ for commercial pullulan blended with PVA whereas the diameter range was 180 to $220 \mathrm{~nm}$ for pullulan extracted from A. pullulans and A. pullulans MTCC 1991 blended with PVA (see Table 5).

Table 5 Size analysis of electrospun nanofibre mats of pullulan using SEM images 


\begin{tabular}{|lll|}
\hline Sr. No. & Electrospun nanofibre mats & $\begin{array}{c}\text { Diameter in } \mathrm{nm} \\
\text { (Average } \pm \text { SD) }\end{array}$ \\
\hline 1. & Commercial pullulan & $838 \pm 53$ \\
\hline 2. & PVA & $494 \pm 74$ \\
\hline 3. & Commercial pullulan $+40 \%$ PVA & $179 \pm 19$ \\
\hline 4. & Commercial pullulan $+50 \%$ PVA & $130 \pm 23$ \\
\hline 5. & A. pullulans MTCC 1991 pullulan $+40 \%$ PVA & $213 \pm 78$ \\
\hline 6. & A. pullulans pullulan $+50 \%$ PVA & $183 \pm 33$ \\
\hline
\end{tabular}

The AFM images (Fig. 7) as analyzed in the SPM lab software showed that the fibres obtained on electrospinning of commercial pullulan and PVA were larger in height and diameter as compared to their blended fibres (Table 6). Also, the extracted pullulans blended with PVA not only gave thinner fibres than commercial polymer but also gave fibres in the nano-size range.

Table 6 AFM analysis of pullulan / PVA nanofibres at $2 \mu \mathrm{m}$ magnification

\begin{tabular}{|llllll|}
\hline $\begin{array}{l}\text { Sr. } \\
\text { No. }\end{array}$ & $\begin{array}{l}\text { Electrospun pullulan } \\
\text { nanofibre mats }\end{array}$ & $\begin{array}{l}\text { Average Height } \\
(\mathrm{nm}) \pm \text { SD }\end{array}$ & $\begin{array}{l}\text { Average Diameter } \\
(\mathrm{nm}) \pm \text { SD }\end{array}$ & $\begin{array}{l}\text { Average Roughness } \\
(\mathrm{nm}) \pm \text { SD }\end{array}$ & $\begin{array}{l}\text { Average Surface area } \\
(\boldsymbol{\mu m})^{2} \pm \text { SD }\end{array}$ \\
\hline 1. & Commercial pullulan & $145 \pm 21$ & $897 \pm 42$ & $14.2 \pm 0.002$ & $4.33 \pm 1.6$ \\
\hline 2. & PVA & $240 \pm 35$ & $1210 \pm 78$ & $35.5 \pm 0.007$ & $5.18 \pm 0.4$ \\
\hline 3. & Commercial + 40\% PVA & $84 \pm 14$ & $413 \pm 25$ & $14.7 \pm 0.0036$ & $4.22 \pm 2.1$ \\
\hline 4. & Commercial + 50\% PVA & $15.82 \pm 3.5$ & $128 \pm 16$ & $13.1 \pm 0.0015$ & $4.09 \pm 1.2$ \\
\hline 5. & $\begin{array}{l}\text { A. pullulans MTCC 1991+ } \\
\text { 40\% PVA }\end{array}$ & $15.59 \pm 4.2$ & $260 \pm 32$ & $9.464 \pm 0.0024$ & $4.13 \pm 2.7$ \\
\hline 6. & A. pullulans $+50 \%$ PVA & $28.72 \pm 8.8$ & $383 \pm 39$ & $25.2 \pm 0.009$ & $4.07 \pm 1.8$ \\
\hline
\end{tabular}

The BET analysis data measuring the average pore radius, total pore volume are given in the table 7 . The average pore radius (8.664 $⿱$ ) $)$ was smallest in case of the electrospun nanofibre mat produced from commercial pullulan $+40 \% \mathrm{PVA}$. The total pore volume $(0.08785 \mathrm{cc} / \mathrm{g})$ was lowest in case of the electrospun nanofibre mat produced from $A$. pullulans pullulan $+50 \% \mathrm{PVA}$. The surface area $\left(1302 \mathrm{~m}^{2} / \mathrm{g}\right)$ was the highest in case of the electrospun nanofibre mat produced from PVA alone. The surface area for commercial pullulan alone was found to be $183.4 \mathrm{~m}^{2} / \mathrm{g}$. But the surface areas of their blended solutions were more than $183.4 \mathrm{~m}^{2} / \mathrm{g}$, this is attributed to the high surface area of PVA nanofibres.

Table 7 BET analysis of electrospun nanofibre mats of pullulan 


\begin{tabular}{|lllll|}
\hline $\begin{array}{l}\text { Sr. } \\
\text { No. }\end{array}$ & $\begin{array}{l}\text { Electrospun pullulan } \\
\text { nanofibre mats }\end{array}$ & $\begin{array}{l}\text { Average Pore Radius }(\AA) \\
\mathbf{\AA} \text { SD }\end{array}$ & $\begin{array}{l}\text { Average Total Pore Volume } \\
(\mathbf{c c} / \mathbf{g}) \pm \text { SD }\end{array}$ & $\begin{array}{l}\text { Average Surface area } \\
\left(\mathbf{m}^{2} / \mathbf{g}\right) \pm \text { SD }\end{array}$ \\
\hline 1. & Commercial pullulan & $15.20 \pm 0.072$ & $0.1394 \pm 0.002$ & $183.4 \pm 5.7$ \\
\hline 2. & PVA & $17.4 \pm 0.085$ & $1.133 \pm 0.009$ & $1302 \pm 32$ \\
\hline 3. & Commercial + 40 \% PVA & $8.664 \pm 0.041$ & $0.1027 \pm 0.0015$ & $237 \pm 11$ \\
\hline 4. & Commercial + 50 \% PVA & $18.08 \pm 0.1$ & $0.2003 \pm 0.004$ & $221.6 \pm 9.5$ \\
\hline 5. & $\begin{array}{l}\text { A. pullulans MTCC 1991+ } \\
\text { 40\% PVA }\end{array}$ & $15.61 \pm 0.079$ & $0.1176 \pm 0.0024$ & $150.68 \pm 4.5$ \\
\hline 6. & A. pullulans $+50 \%$ PVA & $11.81 \pm 0.065$ & $0.08785 \pm 0.0023$ & $148.8 \pm 8$ \\
\hline
\end{tabular}

Electrospun mat of pullulan without carrier polymer had contact angle of $57.5^{\circ}$ indicating the hydrophilic nature of pullulan and, the electrospun mat of only PVA has the contact angle of $108.7^{\circ}$ indicating the hydrophobic nature. The electrospun mats of blended polymers had contact angle of $101.3^{\circ}$ for Commercial pullulan $+40 \%$ PVA, $110.4^{\circ}$ for Commercial pullulan $+50 \%$ PVA, $98.0^{\circ}$ for $A$. pullulans MTCC 1991 pullulan + 40\% PVA, 104.7 for A. pullulans pullulan + 50\% PVA.

In the DSC analysis, the electrospun pullulan mat without PVA did not show any endothermic peak around $220^{\circ} \mathrm{C}$, which is attributed to melting temperature of PVA (Fig. 8). This peak was prominent in all the electrospun blended mats of pullulan and PVA at around $220^{\circ} \mathrm{C}$.

As per the CIE colour space analysis, the lightness value, $L^{*}$, represents the darkest black at $L^{*}=0$, and the brightest white at $L^{*}=$ 100. The $L^{*}$ (Lightness) values obtained for electrospun commercial pullulan was 91 whereas $L^{*}$ values for electrospun pullulan extracted from, A. pullulans MTCC 1991 and A. pullulans were 91 and 90 respectively When compared to standard white paper on which the electrospinning was carried out, $\Delta \mathrm{L}^{*}$ values for electrospun, commercial pullulan, pullulan extracted from A. pullulans MTCC 1991 and $A$. pullulans were $2.408,1.394$ and 1.367 , respectively. The redness/greenness color component, a*, negative values indicate greenness while positive values indicate redness. The, $a^{*}$, values obtained for electrospun commercial pullulan was 2.126 whereas for electrospun pullulan extracted from, A. pullulans MTCC 1991 and A. pullulans were -0.006 and 1.090 respectively. The blueness/yellowness color component, $b^{\star}$, negative values indicate blueness while positive values indicate yellowness. The, $b^{\star}$, values obtained for electrospun commercial pullulan was -3.051 whereas for electrospun pullulan extracted from, A. pullulans MTCC 1991 and A. pullulans were 4.556 and 1.078 respectively. When the magnitude of the color difference, $\Delta \mathrm{E}^{\star}$, is higher than 1 , it indicates a visually detectable color difference and its value increases further for greater color changes. When compared to standard white paper on which the electrospinning was carried out, $\Delta \mathrm{E}^{*}$ values for electrospun, commercial pullulan, pullulan extracted from A. pullulans MTCC 1991 and $A$. pullulans were $6.995,16.219$ and 12.873 respectively.

\section{Discussion:}

Results of SEM and measurement of average diameter range of nanofibers indicated that the addition of PVA helps to reduce the diameter of nanofibres out of pullulan. Earlier work reported the diameter of composite pullulan-whey protein nanofibers made by electrospinning to be $231 \mathrm{~nm}$ (Drosou et al. 2018).

As per the results of AFM, the height and diameter of nanofibres increased by $40 \%$ and $70 \%$ for pullulan extracted from $A$. pullulans whereas it decreased by $40 \%$ and $35 \%$ for pullulan extracted from A. pullulans MTCC 1991, respectively, when compared to the nanofibres of commercial pullulan / PVA blend. The roughness of pullulan nanofibres increased by $45 \%$ and $10 \%$ for pullulans extracted from A. pullulans and filamentous yeast, respectively whereas it decreased by $35 \%$ for pullulan extracted from A. pullulans MTCC 1991 as compared to the commercial pullulan / PVA blend. In case of measurement of surface area, the difference in the extracted pullulan and commercial were less than $5 \%$. Overall surface area calculated for all the samples were not significantly different.

As per the BET results in Table 7, the average pore radius electrospun nanofibres from pullulan of A. pullulans MTCC $1991+40 \%$ PVA was $80 \%$ more than its comparable commercial pullulan with 40\% PVA. But, the average pore radius electrospun nanofibres from pullulan of $A$. pullulans $+50 \%$ PVA was $35 \%$ lesser than its comparable commercial pullulan with $50 \%$ PVA. The total pore volume of electrospun nanofibres from pullulan of $A$. pullulans $+50 \%$ PVA is $56 \%$ lesser than its comparable commercial pullulan with $50 \%$ PVA. On 
the other hand, the total pore volume of electrospun nanofibres from pullulan of $A$. pullulans MTCC $1991+40 \%$ PVA was $14.5 \%$ more than its comparable commercial pullulan with 40\% PVA. Thus, extracted pullulan gave better average pore radius and total pore volume as compared to commercial when same amount of PVA carrier polymer was added. The surface area of electrospun nanofibres from pullulan of $A$. pullulans MTCC $1991+40 \%$ PVA was $36.4 \%$ less than its comparable commercial pullulan with $40 \%$ PVA. The surface area of electrospun nanofibres from pullulan of $A$. pullulans $+50 \%$ PVA was $32 \%$ less than its comparable commercial pullulan with $50 \%$ PVA. This proves that finest nanofibres were produced from extracted pullulan from A. pullulans $+50 \%$ PVA. The surface area obtained in this work is very much higher than the reported value of $17.6 \mathrm{~m}^{2} / \mathrm{g}$ in case of electrospun gelatin nanofibres (Jakub et al. 2012) and 19.49

$\mathrm{m}^{2} / \mathrm{g}$ in case of $\beta$-Cyclodextrin based electrospun nanofibers (Zhao et al. 2015). Similar result was reported earlier wherein a facile route for fabrication of novel microporous material based on chitosan and PVA nanofibres resulted in high specific surface area $\left(1680 \mathrm{~m}^{2} / \mathrm{g}\right)$, considerably small, pore volume $(0.061 \mathrm{cc} / \mathrm{g})$, and small pore radius $(0.08 \AA)$, as proved by BET analysis (Sargazi et al. 2018).

The wettability of a material surface is an important property that is described as the contact angle between the liquid and the material surface. It clearly showed that as the presence of PVA imparted hydrophobic effect to the electrospun pullulan mat. In all the cases, the contact angle of the blended polymer electrospun mat was in between that of pure pullulan and pure PVA. In an earlier report, the fluorinated silane functionalized superhydrophobic pullulan/poly(vinyl alcohol) blend membrane with water contact angle larger than $150^{\circ}$ was prepared by the electrospinning method and characterized (Karim et al. 2011). Another study was reported earlier wherein the hydrophobicity was introduced in the biodegradable films using PVA (Karim et al. 2011; Dominguez-Martinez et al. 2017).

As per the DSC curves, the dramatic changes observed in the melting temperature of the blended mat can be attributed by the introduction of $\mathrm{CF} 3$ groups into heteroatom ( $\mathrm{O}$ atom) containing hydrophobic carbon ring of pullulan and hydrophobic carbon chain of PVA (Zalar et al. 2008; Liu et al. 2013; Karim et al. 2011).

As per the CIE colour space analysis, no significant difference in whiteness ( $\left.L^{*}\right)$ was observed among various pullulan samples. The electrospun mat of extracted pullulan was darker than that of commercial pullulan as per the values of $\Delta \mathrm{L}^{*}$. The commercial pullulan and one extracted from $A$. pullulans were found be having redness color component whereas pullulan extracted from $A$. pullulans MTCC 1991 was found to be having greenness color component as per the values of $a^{*}$. The commercial pullulan was found to be having blueness color component whereas pullulan extracted from A. pullulans MTCC 1991 and A. pullulans MTCC 1991 were found to be having yellowness color component as per the values of $\mathrm{b}^{\star}$. According to the values of $\Delta \mathrm{E}^{\star}$, mat from electrospun extracted pullulan is having significant color difference than that of commercial pullulan.

\section{Conclusion}

The isolate, A. pullulans yielded more pullulan $\left(67.4 \mathrm{gL}^{-1}\right)$ as compared to A. pullulans MTCC $1991\left(63.68 \mathrm{gL}^{-1}\right)$ in solid state fermentation. Wheat Bran, a low-cost and easily available waste material from wheat flour production, could provide an economic advantage as a solid substrate as well as sole carbon source for production of the pullulan by A. pullulans isolated from the Peltophorum species. Even though the specific surface area of the commercial pullulan was higher than the extracted pullulan nanofibres, the average pore size and total pore volume for extracted pullulan nanofibres were lesser than the commercial as calculated by BET analysis, indicating finer nanofibre formation. This in turn could be helpful for application based on retaining ability of the nanofibre mats at the nano level and thereby increasing the efficiency of the product. The pullulan extracted from A. pullulans MTCC 1991 as well as isolate, $A$. pullulans could be electrospun into nanofibres only when blended with PVA (40 -50\%). The significant change in melting temperature of the blended electrospun mats as observed in DSC thermograms could be attributed to the addition of PVA. This work provides newer isolates for production of pullulan using wheat bran as carbon source and also the process protocol for production of nanofibre mat by electrospinning after blending with PVA.

\section{List Of Abbreviations}

XRD X-ray diffractometer

BET Brunauer-Emmett-Teller

PVA poly (vinyl alcohol)

EPS exopolysaccharide

SF submerged fermentation 
WB Wheat Bran

CSD Cotton Stalk Dust

SSF Solid State Fermentation

S.D. standard deviation

IPA Isopropyl alcohol

PEG 600 Polyethylene glycol 600

PDA Potato Dextrose Agar

YMA Yeast Morphology Agar

MEA Blakeslee's Malt Extract Agar

YNB Yeast Nitrogen Base

YCB Yeast Carbon Base

NCMR National Centre for Microbial Resource

APD automatic powder diffraction

FT-IR Fourier transform infrared

STP standard temperature and pressure

TCD tip to collector distance

SEM scanning electron microscope

AFM Atomic Force Microscope

CIE International Commission of Illumination

NFCCI National Fungal Culture Collection of India

ITS Internal transcribed spacer

TIFR Tata Institute for Fundamental Research

\section{Declarations}

\section{Ethics approval and consent to participate}

Not applicable.

\section{Consent for publication}

Not applicable.

\section{Availability of data and materials}

All data generated or analysed during this study are included in this published article.

\section{Competing interests}

The authors declare that they have no competing interests. 


\section{Funding}

All the research work was funded by ICAR - Central Institute for Research on Cotton Technology, Matunga, Mumbai 400019, India.

\section{Authors' contributions}

KS performed all the experimental methods and interpretation was carried out jointly by KS and NV.

\section{Acknowledgements}

Authors acknowledge the support provided by Dr. P.G. Patil, Dr. S. Saxena, Dr. Charlene D’ Souza, Dr. Nandita Ashtaputre, Mr. Nishant Kambli, Mr. Rajesh Kadam, Mr. Rajesh Narkar, Mr. G. B. Hadge and Mr. Prabhu Desai of ICAR-Central Institute for Research on Cotton Technology, Mumbai, India. Authors also acknowledge the support provided by the National Facility for High-field NMR, Tata Institute for Fundamental Research (TIFR), Colaba, Mumbai, India and National Fungal Culture Collection of India (NFCCI)-A National Facility, Agharkar Research Institute, Pune, India.

\section{References}

1. Ray PC, Moorthy SN (2007) Exopolysachharide (pullulan) production from cassava starch residue by Aureobasidium pullulans strain MTCC 1991. J Sci Ind Res (India) 66:252-255

2. Singh RS, Saini GK, Kennedy JF (2008) Pullulan: Microbial sources, production and applications. Carbohydr Polym 73(4):515-531

3. Leathers TD (2003) Biotechnological production and applications of pullulan. Appl Microbiol Biotechnol 62(5):468-473

4. Knapp BK, Parsons CM, Bauer LL, Swanson KS, Fahey GC (2010) Soluble Fiber Dextrins and Pullulans Vary in Extent of Hydrolytic Digestion in Vitro and in Energy Value and Attenuate Glycemic and Insulinemic Responses in Dogs. J Agric Food Chem 58(21):11355-11363

5. Kong L, Ziegler GR (2014) Rheological aspects in fabricating pullulan fibers by electro-wet-spinning. Food Hydrocoll 38:220-226

6. Pollock TJ, Thorne L, Armentrout RW (1992) Isolation of new aureobasidium strains that produce high-molecular-weight pullulan with reduced pigmentation. Appl Environ Microbiol 58(3):877-883

7. Punnapayak H, Sudhadham M, Prasongsuk S, Pichayangkura S (2003) Characterization of Aureobasidium pullulans isolated from airborne spores in Thailand. J Ind Microbiol Biotechnol 30(2):89-94

8. Kang J-x, Chen X-j, Chen W-r, Li M-s, Fang Y, Li D-s, Ren Y-z, Liu D-q (2011) Enhanced production of pullulan in Aureobasidium pullulans by a new process of genome shuffling. Process Biochem 46(3):792-795

9. Prasongsuk S, Lotrakul P, Ali I, Bankeeree W, Punnapayak H (2018) The current status of Aureobasidium pullulans in biotechnology. Folia Microbiol 63(2):129-140

10. Urzi C, De Leo F, Lo Passo C, Criseo G (1999) Intra-specific diversity of Aureobasidium pullulans strains isolated from rocks and other habitats assessed by physiological methods and by random amplified polymorphic DNA (RAPD). J Microbiol Methods 36(1-2):95105

11. Yurlova NA, Uijthof JMJ, de Hoog GS (1996) Distinction of species in Aureobasidium and related genera by PCR-ribotyping. Antonie van Leeuwenhoek 69(4):323

12. Zalar P, Gostincar C, de Hoog GS, Ursic V, Sudhadham M, Gunde-Cimerman N (2008) Redefinition of Aureobasidium pullulans and its varieties. Stud Mycol 61:21-38

13. Yurlova N, Hoog S, Gerrits van den Ende B (1999) Taxonomy of Aureobasidium and allied genera. Stud Mycol 43:63-69

14. Limtong S, Koowadjanakul N (2012) Yeasts from phylloplane and their capability to produce indole-3-acetic acid. World J Microbiol Biotechnol 28(12):3323-3335

15. Youssef F, Biliaderis CG, Roukas T (1998) Enhancement of pullulan production by aureobasidium pullulans in batch culture using olive oil and sucrose as carbon sources. Appl Biochem Biotechnol 74(1):13-30

16. Kim J-H, Kim M-R, Lee J-H, Lee J-W, Kim S-K (2000) Production of high molecular weight pullulan by Aureobasidium pullulans using glucosamine. Biotechnol Lett 22(12):987-990

17. Glushakova AM, Chernov IY (2010) Seasonal dynamics of the structure of epiphytic yeast communities. Microbiology 79(6):830-839

18. SIÁviková E, Vadkertiová R, Vránová D (2009) Yeasts colonizing the leaves of fruit trees. Ann Microbiol 59(3):419-424 
19. Landell MF, Billodre R, Ramos JP, Leoncini O, Vainstein MH, Valente P (2010) Candida aechmeae sp. nov. and Candida vrieseae sp. nov., novel yeast species isolated from the phylloplane of bromeliads in Southern Brazil. Int J Syst Evol Microbiol 60(Pt 1):244-248

20. Sharma RR, Singh D, Singh R (2009) Biological control of postharvest diseases of fruits and vegetables by microbial antagonists: A review. Biol Control 50(3):205-221. https://doi.org/10.1016/j.biocontrol.2009.05.001

21. Koowadjanakul N, Jindamorakot S, Yongmanitchai W, Limtong S (2011) Ogataea phyllophila sp. nov., Candida chumphonensis sp. nov. and Candida mattranensis sp. nov., three methylotrophic yeast species from phylloplane in Thailand. Antonie Van Leeuwenhoek 100(2):207-217. https://doi.org/10.1007/s10482-011-9579-9

22. Kunkel ME, Seo A (1994) In Vitro digestibility of selected polymers. J Environ Polym Degrad 2(4):245-251. https://doi.org/10.1007/BF02071972

23. Liu Y, Wang R, Ma H, Hsiao BS, Chu B (2013) High-flux microfiltration filters based on electrospun polyvinylalcohol nanofibrous membranes. Polymer 54(2):548-556. https://doi.org/10.1016/j.polymer.2012.11.064

24. Eslamian M, Khorrami M, Yi N, Majd S, Abidian MR (2019) Electrospinning of highly aligned fibers for drug delivery applications. J Mater Chem B 7(2):224-232. https://doi.org/10.1039/C8TB01258J

25. Kurtzman CP, Fell JW, Boekhout T, Robert V (2011) Methods for Isolation, Phenotypic Characterization and Maintenance of Yeasts. In: Kurtzman CP, Fell JW, Boekhout T (eds) The Yeasts (Fifth Edition). Elsevier, London. https://doi.org/10.1016/B978-0-444-52149$1.00007-0$

26. Choudhury AR, Bhattacharjee P, Prasad GS (2013) Development of Suitable Solvent System for Downstream Processing of Biopolymer Pullulan Using Response Surface Methodology. PLOS ONE 8(10):e77071. https://doi.org/10.1371/journal.pone.0077071

27. Karim MR, Islam MS (2011) Thermal Behavior with Mechanical Property of Fluorinated Silane Functionalized Superhydrophobic Pullulan/Poly(vinyl alcohol) Blends by Electrospinning Method. J Nanomater 2011:7. https://doi.org/10.1155/2011/979458

28. Sharmila G, Muthukumaran C, Nayan G, Nidhi B (2013) Extracellular Biopolymer Production by Aureobasidiumpullulans MTCC 2195 Using Jackfruit Seed Powder. J Polym Environ 21(2):487-494. https://doi.org/10.1007/s10924-012-0459-9

29. de Hoog GS, Yurlova NA (1994) Conidiogenesis, nutritional physiology and taxonomy of Aureobasidium and Hormonema. Antonie van Leeuwenhoek 65(1):41-54. https://doi.org/10.1007/BF00878278

30. Wu J, Zhong F, Li Y, Shoemaker CF, Xia W (2013) Preparation and characterization of pullulan-chitosan and pullulan-carboxymethyl chitosan blended films. Food Hydrocoll 30(1):82-91. https://doi.org/10.1016/j.foodhyd.2012.04.002

31. Xiao Q, Lu K, Tong Q, Liu C (2015) Barrier Properties and Microstructure of Pullulan-Alginate-Based Films. J Food Process Eng 38(2):155-161. https://doi.org/10.1111/jfpe.12151

32. Li R, Tomasula P, De Sousa AMM, Liu S-C, Tunick M, Liu K, Liu L (2017) Electrospinning Pullulan Fibers from Salt Solutions. Polymers 9(1):32

33. Arnosti C, Repeta DJ (1995) Nuclear Magnetic Resonance Spectroscopy of Pullulan and Isomaltose: Complete Assignment of Chemical Shifts. Starch - Stärke 47(2):73-75. https://doi.org/10.1002/star.19950470208

34. Ye L, Zhang J, Ye X, Tang Q, Liu Y, Gong C, Du X, Pan Y (2008) Structural elucidation of the polysaccharide moiety of a glycopeptide (GLPCW-II) from Ganoderma lucidum fruiting bodies. Carbohydr Res 343(4):746-752. https://doi.org/10.1016/j.carres.2007.12.004

35. Sugumaran KR, Jothi P, Ponnusami V (2014) Bioconversion of industrial solid waste-Cassava bagasse for pullulan production in solid state fermentation. Carbohydr Polym 99:22-30. https://doi.org/10.1016/j.carbpol.2013.08.039

36. Sugumaran KR, Sindhu RV, Sukanya S, Aiswarya N, Ponnusami V (2013) Statistical studies on high molecular weight pullulan production in solid state fermentation using jack fruit seed. Carbohydr Polym 98(1):854-860.

https://doi.org/10.1016/j.carbpol.2013.06.071

37. Kim SE, Heo DN, Lee JB, Kim JR, Park SH, Jeon SH, Kwon IK (2009) Electrospun gelatin/polyurethane blended nanofibers for wound healing. Biomed Mater 4(4):044106. https://doi.org/10.1088/1748-6041/4/4/044106

38. Islam MS, Yeum JH, Das AK (2012) Effect of pullulan/poly(vinyl alcohol) blend system on the montmorillonite structure with property characterization of electrospun pullulan/poly(vinyl alcohol)/montmorillonite nanofibers. J Colloid Interface Sci 368(1):273281. https://doi.org/10.1016/j.jcis.2011.11.007

39. Zhang Y, Huang X, Duan B, Wu L, Li S, Yuan X (2007) Preparation of electrospun chitosan/poly(vinyl alcohol) membranes. Colloid Polym Sci 285(8):855-863. https://doi.org/10.1007/s00396-006-1630-4

40. Drosou C, Krokida M, Biliaderis CG (2018) Composite pullulan-whey protein nanofibers made by electrospinning: Impact of process parameters on fiber morphology and physical properties. Food Hydrocoll 77:726-735.

https://doi.org/10.1016/j.foodhyd.2017.11.014

Page 16/23 
41. Jakub S, Hobzov R, Kostina N, Munzarov M, Jukl M, Lhotka M, Kubinov S, Alena Z, Jiri M (2012) Morphological Characterization of Nanofibers: Methods and Application in Practice. J Nanomater 2012:14. https://doi.org/10.1155/2012/327369

42. Zhao R, Wang Y, Li X, Sun B, Wang C (2015) Synthesis of $\beta$-Cyclodextrin-Based Electrospun Nanofiber Membranes for Highly Efficient Adsorption and Separation of Methylene Blue. ACS Appl Mater Inter 7(48):26649-26657. https://doi.org/10.1021/acsami.5b08403

43. Sargazi G, Afzali D, Mostafavi A, Ebrahimipour SY (2018) Synthesis of CS/PVA Biodegradable Composite Nanofibers as a Microporous Material with Well Controllable Procedure Through Electrospinning. J Polym Environ 26(5):1804-1817. https://doi.org/10.1007/s10924-017-1080-8

44. Dominguez-Martinez BM, Martínez-Flores HE, Berrios JDJ, Otoni CG, Wood DF, Velazquez G (2017) Physical Characterization of Biodegradable Films Based on Chitosan, Polyvinyl Alcohol and Opuntia Mucilage. J Polym Environ 25(3):683-691. https://doi.org/10.1007/s10924-016-0851-y

\section{Figures}

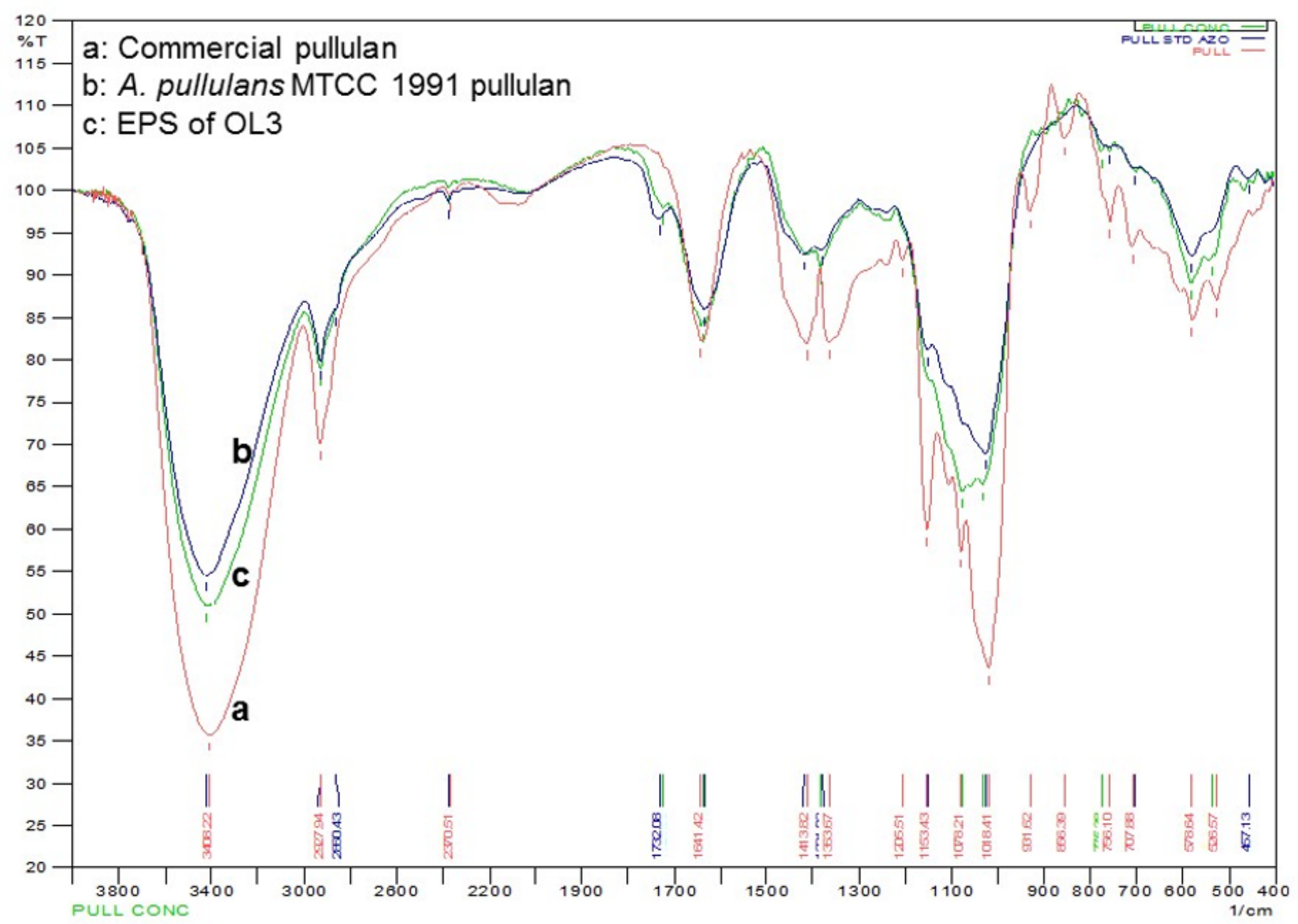

\section{Figure 1}

FTIR spectra of Commercial Pullulan (a), Pullulan of A. pullulans MTCC 1991 (b) and EPS of OL3 (c) 

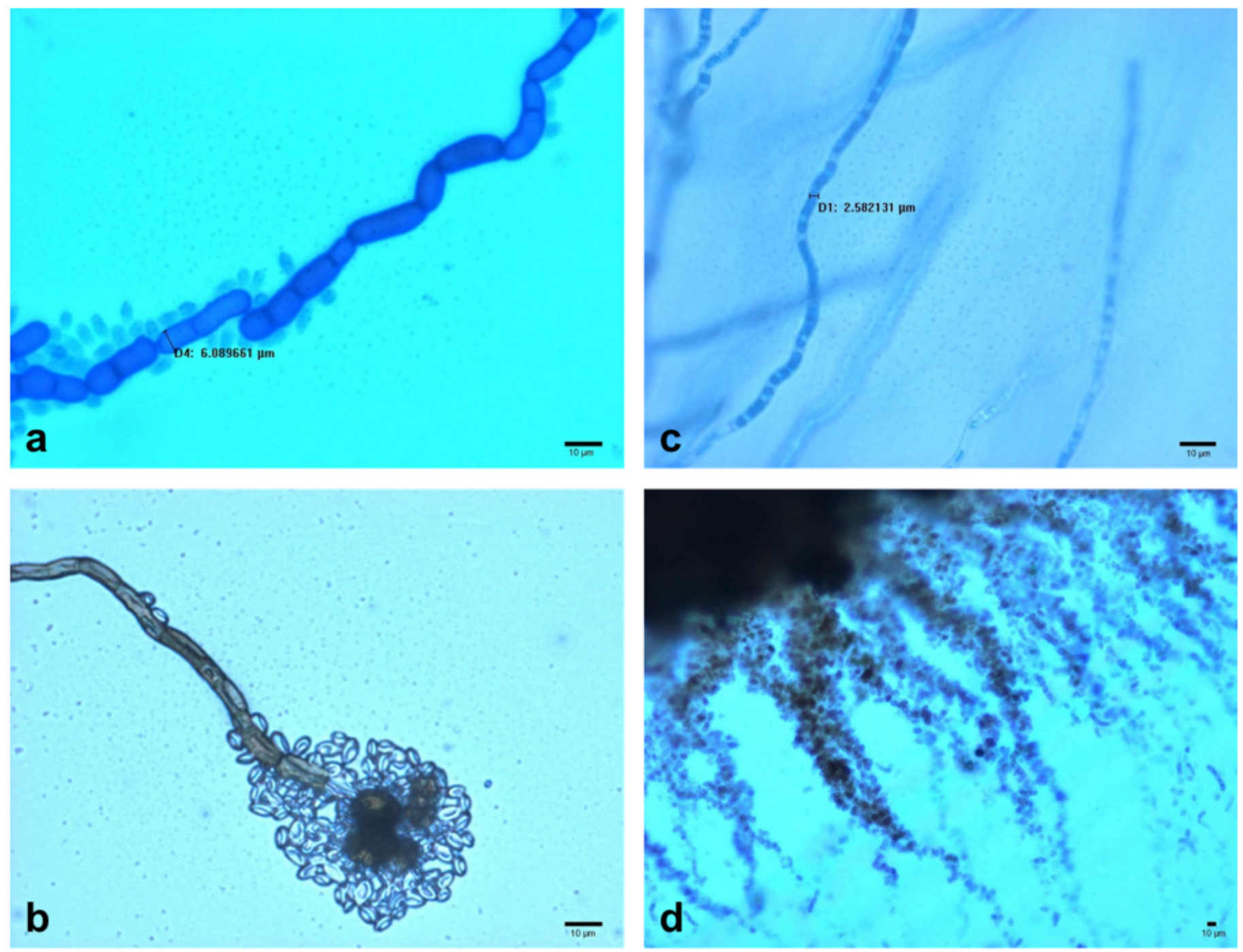

\section{Figure 2}

Microscopic images of A. pullulans MTCC 1991 showing septate hyphae diameter of $6.08 \mu \mathrm{m}$ (a), conidiospore bearing conidia of A. pullulans MTCC 1991 observed at 400x magnification (b), Isolate OL3 showing septate hyphae diameter of $2.34 \mu \mathrm{m}$ (c) and prototunicate asci and blastic conidiogenesis of OL3 observed at 100x magnification (d) 


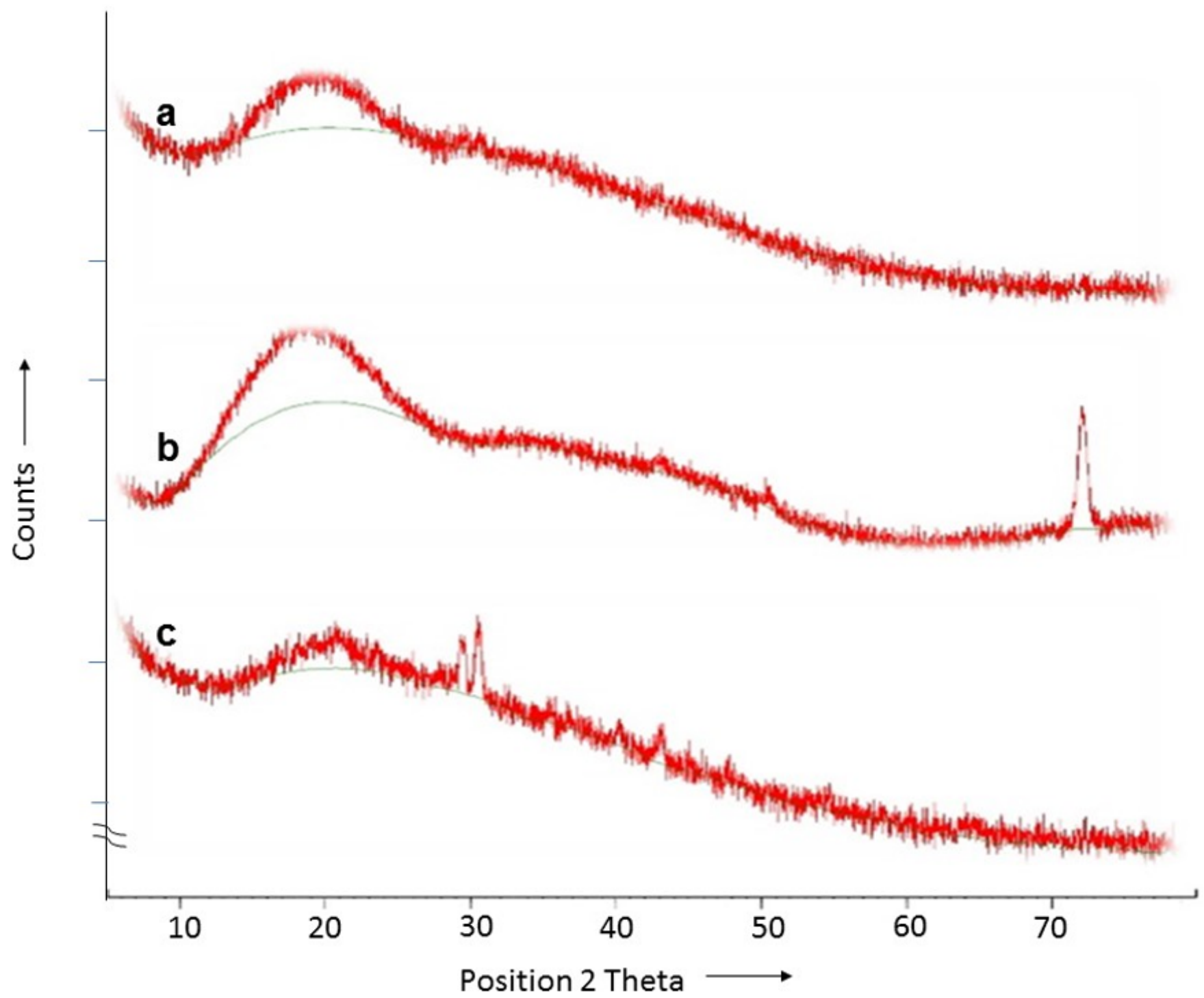

Figure 3

XRD spectra of extracted pullulan from commercial pullulan (a), A. pullulans MTCC 1991 (b) and A. pullulans (c) 


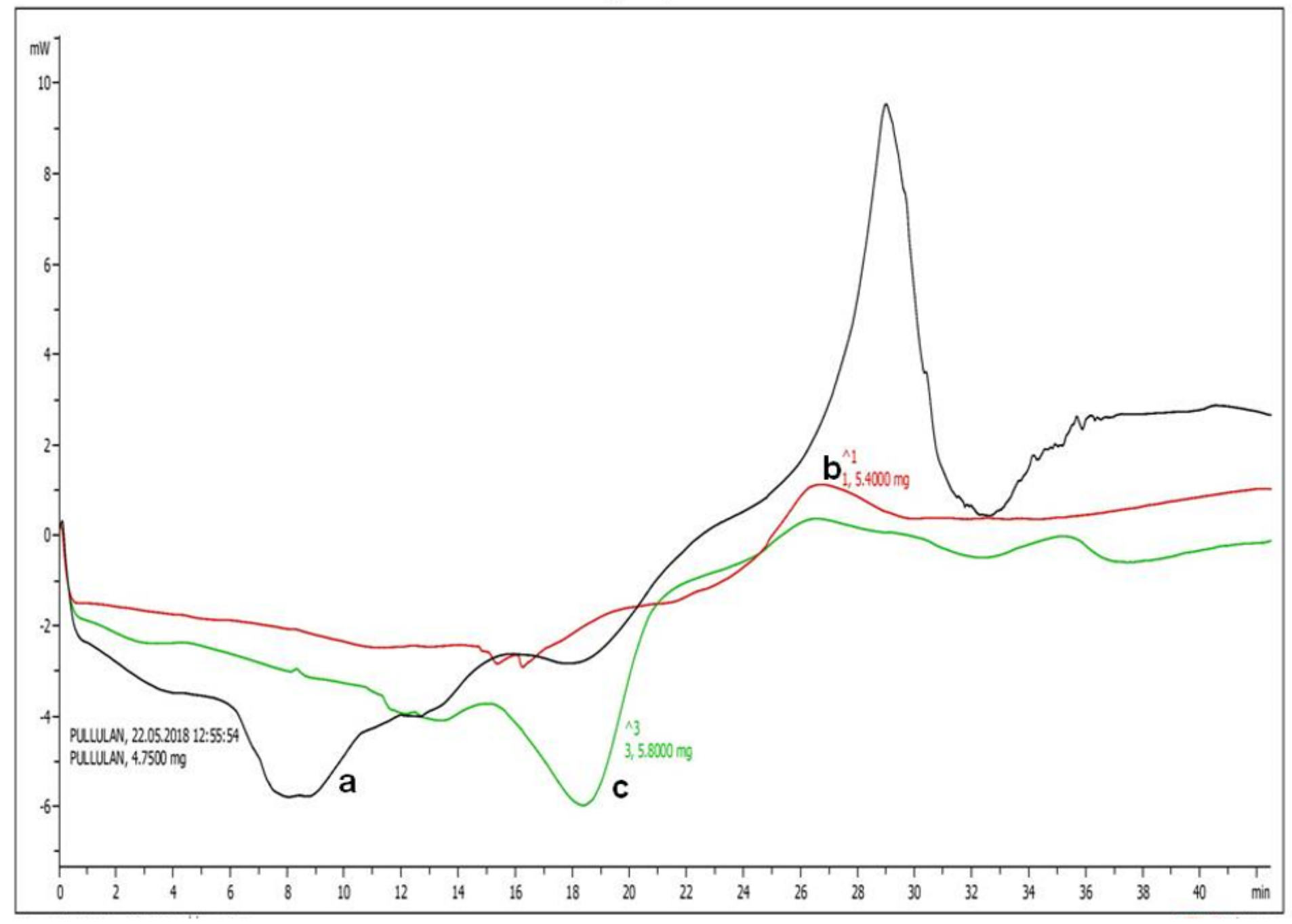

\section{Figure 4}

DSC thermograms of Commercial Pullulan (Black) (a), Pullulan of A. pullulans MTCC 1991 (Red) (b) and Pullulan of A. pullulans (Green) (c) 


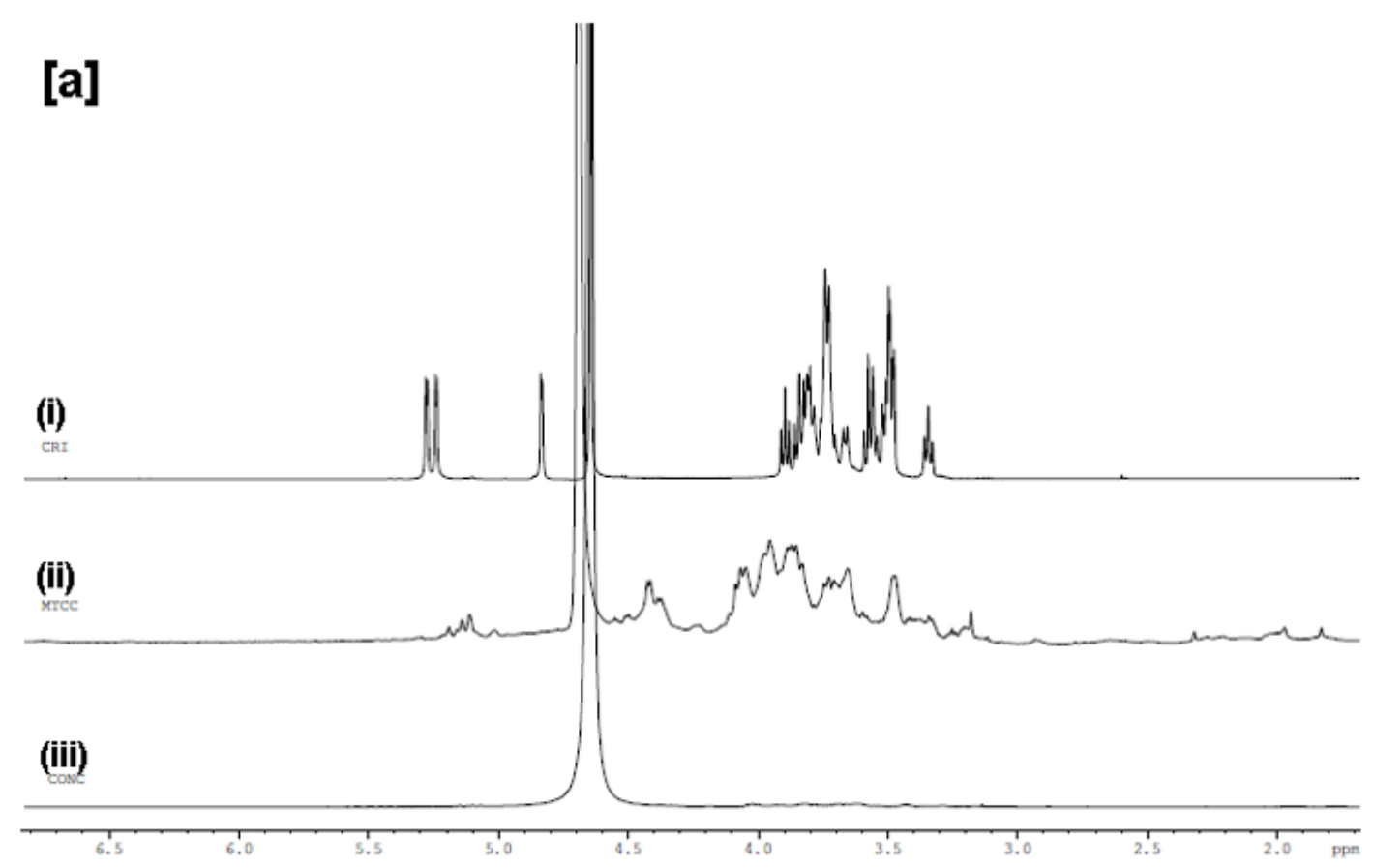

[b]
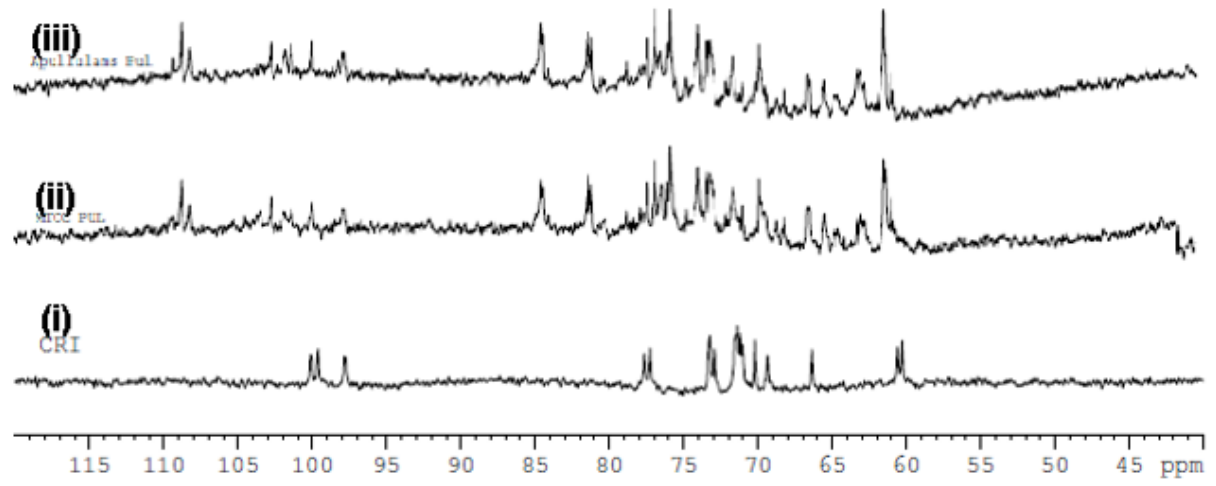

Figure 5

1H-NMR spectra [a] of commercial pullulan (i) and extracted pullulan from A. pullulans MTCC 1991 (ii) and A. pullulans (iii); 13C-NMR spectra [b] of commercial pullulan (i) and extracted pullulan from A. pullulans MTCC 1991 (ii) and A. pullulans (iii) 


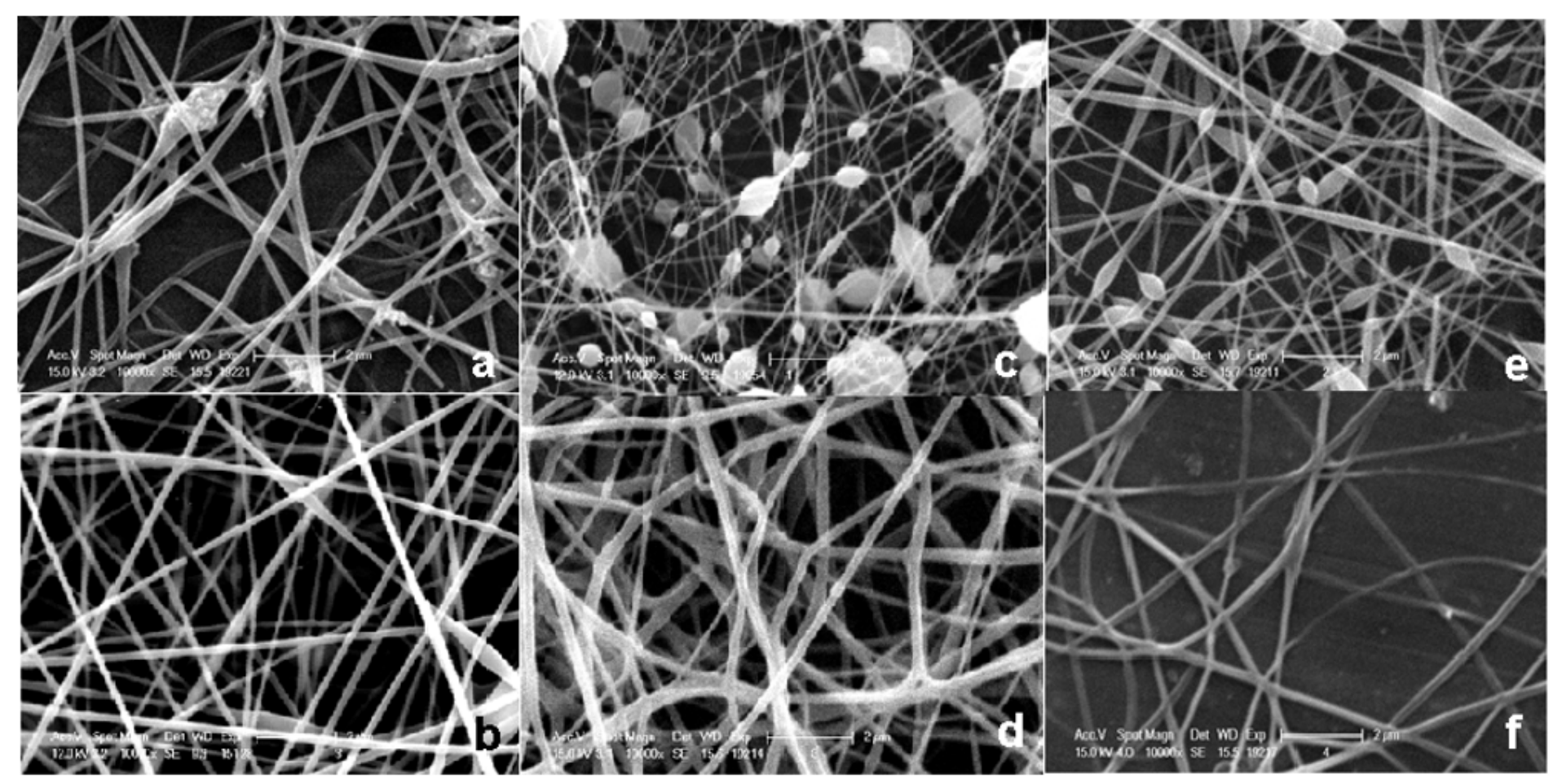

Figure 6

SEM images of electrospun nanofibres of Commercial pullulan (a); Commercial PVA (b); Commercial pullulan with $40 \%$ Poly vinyl alcohol (PVA) (c); Pullulan extracted from A. pullulans MTCC 1991 with 40\% PVA (d); Commercial pullulan with 50\% PVA (e) and Pullulan extracted from A. pullulans with 50\% PVA (f). All images have been taken at 10,000x magnification and scale bars in images represent 2 $\mu \mathrm{m}$
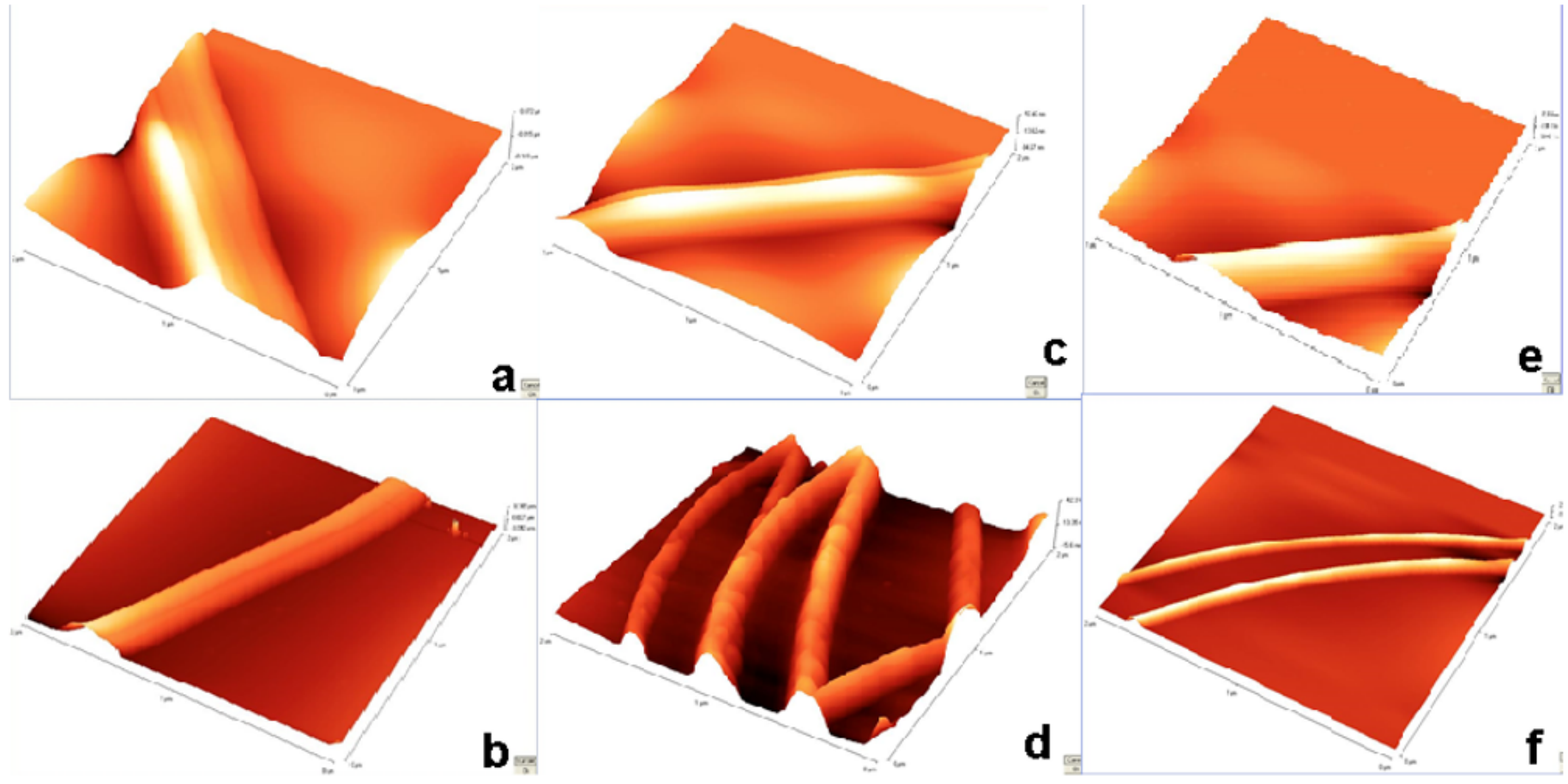

Figure 7 
AFM 3D images of electrospun nanofibres of Commercial pullulan (a); Commercial PVA (b); Commercial pullulan with $40 \%$ Poly vinyl alcohol (PVA) (c); Pullulan extracted from A. pullulans MTCC 1991 with 40\% PVA (d); Commercial pullulan with 50\% PVA (e) and Pullulan extracted from A. pullulans with $50 \%$ PVA (f) at the scale of $2 \mu \mathrm{m}$

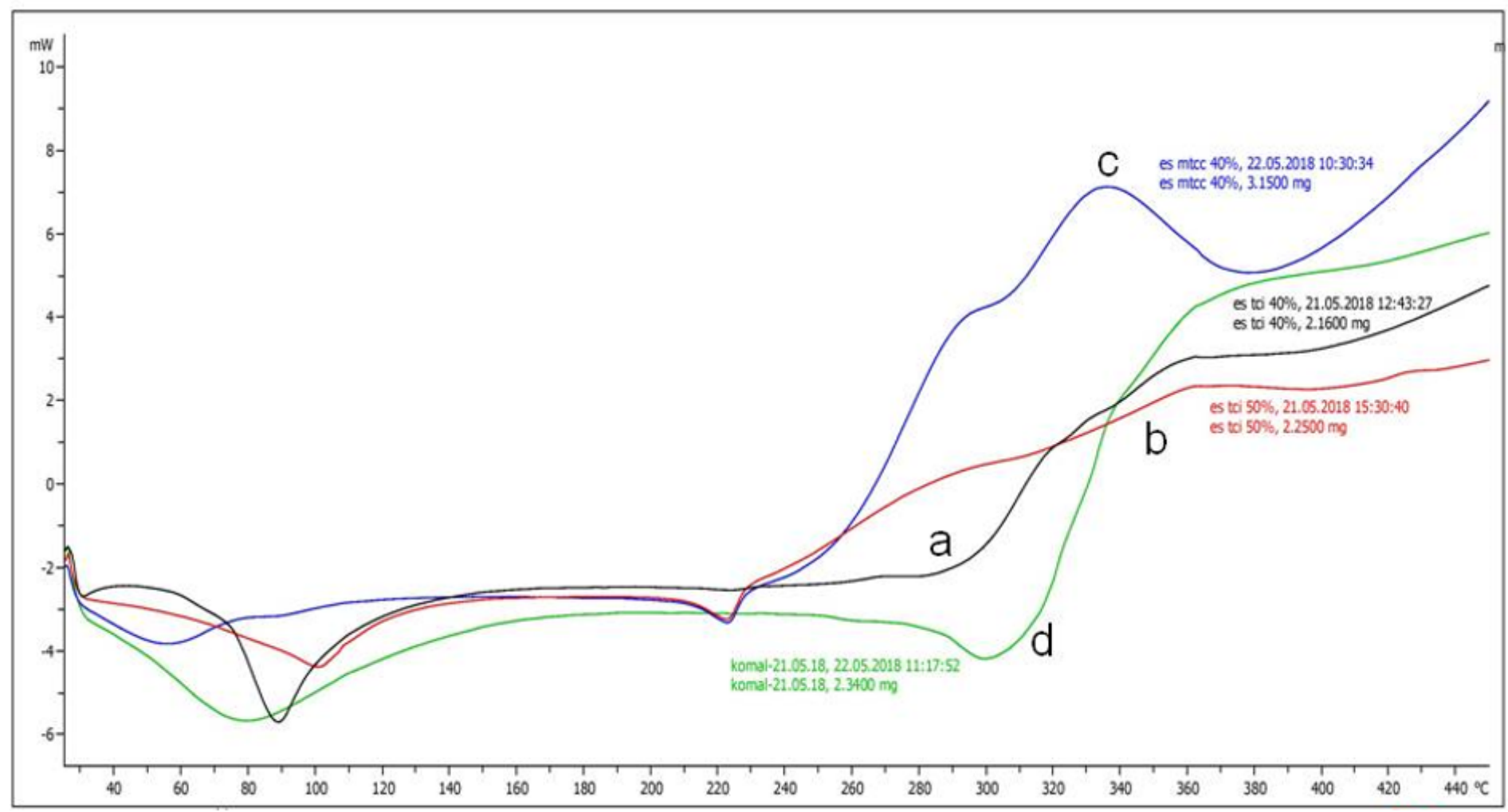

Figure 8

DSC thermogram of electrospun nanofibre mats of commercial pullulan with 40\% PVA (a), commercial pullulan with 50\% PVA (b), pullulan extracted from A. pullulans MTCC $1991+40 \%$ PVA (c) and pullulan extracted from A. pullulans $+50 \%$ PVA (d)

\section{Supplementary Files}

This is a list of supplementary files associated with this preprint. Click to download.

- Graphicalabstract.jpg 